\title{
A Fault Diagnosis Method for Power Transmission Networks Based on Spiking Neural P Systems with Self-Updating Rules considering Biological Apoptosis Mechanism
}

\author{
Wei Liu, ${ }^{1,2}$ Tao Wang $\mathbb{D}^{1,2}$ Tianlei Zang $\mathbb{D}^{\text {, }}{ }^{3,4}$ Zhu Huang, ${ }^{1,2}$ Jun Wang, ${ }^{1,2}$ Tao Huang $\mathbb{D}^{1,5}$ \\ Xiaoguang Wei $\left(\mathbb{D},{ }^{6}\right.$ and Chuan $\mathrm{Li}^{7}$ \\ ${ }^{1}$ School of Electrical Engineering and Electronic Information, Xihua University, Chengdu, China \\ ${ }^{2}$ Key Laboratory of Fluid and Power Machinery, Ministry of Education, Xihua University, Chengdu, China \\ ${ }^{3}$ College of Electrical Engineering, Sichuan University, Chengdu, China \\ ${ }^{4}$ Key Laboratory of Network Assessment Technology, Institute of Information Engineering, Chinese Academy of Sciences, \\ Beijing, China \\ ${ }^{5}$ Department of Energy, Politecnico di Torino, Turin, Italy \\ ${ }^{6}$ School of Electrical Engineering, Southwest Jiaotong University, Chengdu, China \\ ${ }^{7}$ Shandong Electrical Engineering \& Equipment Group Co., Ltd, Shandong, China
}

Correspondence should be addressed to Tao Wang; wangatao2005@163.com and Tianlei Zang; zangtianlei@126.com

Received 12 July 2019; Revised 2 November 2019; Accepted 24 December 2019; Published 21 January 2020

Guest Editor: Francisco G. Montoya

Copyright $(0) 2020$ Wei Liu et al. This is an open access article distributed under the Creative Commons Attribution License, which permits unrestricted use, distribution, and reproduction in any medium, provided the original work is properly cited.

Power transmission networks play an important role in smart girds. Fast and accurate faulty-equipment identification is critical for fault diagnosis of power systems; however, it is rather difficult due to uncertain and incomplete fault alarm messages in fault events. This paper proposes a new fault diagnosis method of transmission networks in the framework of membrane computing. We first propose a class of spiking neural P systems with self-updating rules (srSNPS) considering biological apoptosis mechanism and its self-updating matrix reasoning algorithm. The srSNPS, for the first time, effectively unitizes the attribute reduction ability of rough sets and the apoptosis mechanism of biological neurons in a $\mathrm{P}$ system, where the apoptosis algorithm for condition neurons is devised to delete redundant information in fault messages. This simplifies the complexity of the srSNPS model and allows us to deal with the uncertainty and incompleteness of fault information in an objective way without using historical statistics and expertise. Then, the srSNPS-based fault diagnosis method is proposed. It is composed of the transmission network partition, the SNPS model establishment, the pulse value correction and computing, and the protection device behavior evaluation, where the first two components can be finished before failures to save diagnosis time. Finally, case studies based on the IEEE 14- and IEEE 118-bus systems verify the effectiveness and superiority of the proposed method.

\section{Introduction}

Fast and accurate fault diagnosis is very important for power system restoration after a serious blackout $[1,2]$. This first requires the identification of faulty equipment $[3,4]$. To identify faulty equipment, dispatchers should first analyze the fault alarm messages received from the supervisory control and data acquisition (SCADA) system according to ancillary facilities and their operational experience. Fault events in a power system can cause lots of fault alarm messages, and parts of them may be redundant ones which are not important with respect to the fault. Besides, protection devices may also fail leading to incomplete action information. All these cases can increase the uncertainty and incompleteness of fault alarm messages, making fault diagnosis more difficult [4-7]. Therefore, improving the fault information processing ability of fault diagnosis methods is significant for faulty equipment identification. 
During the past three decades, several fault diagnosis approaches have been developed, such as expert systems (ESs) [8, 9], artificial neural networks (ANNs) [10-14], Bayesian networks (BNs) [15-18], Petri nets (PNs) [19-24], cause-effect networks (CENs) [2, 25], optimization methods (OMs) [26-30], fuzzy logic (FL) $[2,4,10,19-21,23]$, rough sets (RSs) [31-35], and spiking neural P systems (SNPSs) [4, 36-38]. However, each above approach has its limitations which are in detail analyzed in $[1,2,4-6]$. In general, main shortcomings of these methods include (1) strong reliance on a large amount of historical data, such as BNs, PNs, ANNs, and SNPSs; (2) strong dependence on expert experience, such as ESs, BNs, PNs, and SNPSs; (3) poor interpretability of diagnosis results, such as ANNs, OMs, and CENs; (4) poor topological adaptability, such as ANNs, OMs, and BNs; (5) low fault tolerance, such as OMs and ANNs; and (6) cannot be used independently and need to be combined with other methods, such as the FL and RSs. Therefore, how to improve the above methods or put forward new ones is the main issue in the corresponding engineering domain.

Among these fault diagnosis methods, the SNPS is a novel bio-inspired distributed parallel computing model, which has powerful information processing and parallel computing ability (most models have been verified to be Turing equivalent $[39,40])$. The SNPS has become a hot research topic in Membrane Computing [41] and Natural Computing. In recent years, it has been used to explore the new fault information processing mechanism and SNPSbased fault diagnosis methods with rich achievements. SNPSs are a special kind of neural-like P systems [42], inspired by the mechanism that biological neurons store, transmit, and exchange information by pulses (spikes) along axons from presynaptic neurons to postsynaptic neurons in a distributed and parallel manner [4, 43, 44]. Due to the similarity between the spike transmission among different neurons through synapses and the fault propagation in power systems, fault diagnosis models based on different variants of spiking neural $\mathrm{P}$ systems are proposed to reason fault events to find faulty equipment [4, 36-38, 45-49].

At present, SNPS-based fault diagnosis methods can be divided into two categories (according to the fault information processing way): fuzzy reasoning with real numbers (FRRN) [36-38, 45-48] and fuzzy reasoning with fuzzy numbers (FRFN) [4, 50-52]. The FRRN refers to process uncertain and incomplete fault alarm messages using probability numbers which correspond to historical statistics of action information of protection devices including protective relays (PRs) and circuit breakers (CBs). Therefore, the FRRN strongly depends on the historical data. However, with the increasing complexity of power systems, it is difficult to accurately obtain the historical statistics and update them in time. For the second kind of method, the FRFN is to deal with the uncertainty and incompleteness by fuzzy numbers. Wang et al. [4], for the first time, introduces trapezoidal fuzzy numbers, fault fuzzy production rules, and fault confidence levels into the framework of SNPSs to propose a fault diagnosis method for power transmission networks, where neurons, spikes, firing rules, and firing conditions are redefined. Then, Tao et al., Yu et al., and Peng et al. [50-52] continue to explore and introduce triangular fuzzy numbers, interval valued fuzzy numbers, and intuitionistic fuzzy sets, respectively, to diagnose faults of transmission networks. However, for abovementioned types of FRFN, the different kinds of fuzzy numbers are all obtained via expert experience. Therefore, the FRFN has high subjectivity, and its nonsubjectivity is still a difficult problem to be solved. In addition, both the FRRN and the FRFN do not consider the preprocessing of fault alarm messages, that is, the fault alarm messages cannot be effectively utilized by deleting redundant information before modeling the SNPS-based diagnosis models. Therefore, when the scale and complexity [53-56] of a power system increase and the redundancy of fault information is high, the fault tolerance of SNPS-based methods will reduce rapidly. Therefore, more attention should be paid to how to effectively overcome the above shortcomings.

On the contrary, the rough set $[57,58]$ is a typical mathematical tool to deal with uncertain and imprecise information in an objective way. However, the rough set generally should be combined with other methods because it can only reason and calculate fault data itself weakly. To address the aforementioned issues, this paper first proposes a spiking neural $\mathrm{P}$ system with self-updating rules (srSNPS) considering biological apoptosis mechanism, which integrates the strong objectivity (i.e., no need of any priori or additional information [59]) and good uncertainty handling capacity of rough sets and excellent parallel information processing ability of SNPSs. Then, an srSNPS-based fault diagnosis method for transmission networks is further devised. The main contributions of this paper are described as follows:

(1) To effectively deal with uncertain and incomplete fault information in an objectivity way, an srSNPS and its apoptosis algorithm (Algorithm 1) for condition neurons are proposed. This is the first time to availably unify the attribute reduction function of rough sets and the apoptosis mechanism of biological neurons in the framework of membrane computing. This way makes the SNPSs handle the uncertainty and incompleteness without historical statistics and expert experience.

(2) Besides, the self-updating matrix reasoning algorithm (Algorithm 2) and self-updating rules for input neurons are proposed. So, the srSNPS can effectively make comprehensive use of fault information including action information, start information, and overlimit signals of protection devices to improve its uncertainty and incomplete processing capacity based on a simple matrix reasoning process with a vivid graphical modelbuilding way. 
Input: $t$ condition neurons, $s$ decision-making neurons

(1) Calculate $h(C)$ via (2) and let $L=C$

(2) while $(j \leq t)$

(3) Calculate $h\left(C-C_{j}\right)$ after the $C_{j}$ dies via (2)

(4) Calculate the importance degree $\operatorname{Sig}\left(C_{j}\right)$ of the $C_{j}$ via (1)

(5) if $\operatorname{Sig}\left(C_{j}\right)=0$, then

(6) $L=C-\left\{C_{i}\right\}$

(7) else

(8) $L=C$

(9) end if

(10) end while

Output: survival condition neuron set $L$

Algorithm 1: Apoptosis algorithm for condition neurons.

(1) Let $g=0$

(2) if input neurons satisfy with the firing conditions of self-updating rules, then

(3) correct $\boldsymbol{\theta}_{g}$ and the algorithm jumps to Step 7

(4) else

(5) the algorithm jumps to Step 7 without pulse value correction

(6) end if

(7) while $\left(\boldsymbol{\theta}_{g} \neq \mathbf{0}_{1}\right.$ or $\left.\boldsymbol{\delta}_{g} \neq \mathbf{0}_{2}\right)$

(8) if proposition neurons satisfy their firing conditions then

(9) proposition neurons fire and compute $\boldsymbol{\delta}_{g+1}$ via

(10) end if $\boldsymbol{\delta}_{g+1}=\left(\mathbf{D}_{1}^{T} \otimes \boldsymbol{\theta}_{g}\right)+\left(\mathbf{D}_{2}^{T} \cdot \boldsymbol{\theta}_{g}\right)+\left(\mathbf{D}_{3}^{T} \circ \boldsymbol{\theta}_{g}\right)$

(11) if rule neurons satisfy their firing conditions then

(12) rule neurons fire and compute $\boldsymbol{\theta}_{g+1}$ via

(13) end if

$$
\boldsymbol{\theta}_{g+1}=\mathbf{E}^{T} \circ \boldsymbol{\delta}_{g+1}
$$

(14) $g=g+1$

(15) end while

Output: Pulse values of output neurons

Algorithm 2: Self-updating matrix reasoning algorithm.

(3) Based on the proposed srSNPS and two algorithms, combined with the depth-first search algorithm (DSA), the weight network segmentation method (WNSM) and the protection device event tree (PDET), an srSNPS-based fault diagnosis method is proposed. This method has good diagnosis result interpretability while maintaining high-fault tolerance and a fast diagnosis speed under the uncertainty and incompleteness of fault alarm messages. In addition, it does not require historical statistics and expertise. These are not the case for previous SNPSbased methods (even for all the graphical reasoning diagnosis methods).

The remainder of this paper is organized as follows. Section 2 proposes the srSNPS and its algorithms. The srSNPS-based fault diagnosis method is proposed in Section 3. In Section 4, the proposed diagnosis method is applied to the IEEE 14- and 118-bus systems with the analysis of their effectiveness and superiority. Conclusions are finally drawn in Section 5.

\section{Spiking Neural P Systems with Self- Updating Rules}

This section first proposes the srSNPS and then presents its SMRA.

\subsection{Spiking Neural P Systems with Self-Updating Rules}

Definition 1. A spiking neural $\mathrm{P}$ system with self-updating rules (srSNPS) is a tuple:

$$
\Pi=\left(O, M_{e}, \sigma_{1}, \ldots, \sigma_{m}, \text { syn, in, out }\right),
$$

where

(1) $O=\{a\}$ is a singleton alphabet ( $a$ is called a spike, $O$ is a set of spikes).

(2) $M_{e}=\left(D_{i}, C_{j}\right)$ is called microenvironment, where

(a) $D_{i}=\left(\theta_{d i / T}, T, f_{i}\right), 1 \leq i \leq s$, is the $i$-th decisionmaking neuron (DN) in $M_{e}$ and represents 
suspicious faulty equipment in the targeted power network, where

(i) $\theta_{d i / T}$ equals to 0 or 1 representing the pulse value of the $i$-th $\mathrm{DN}$ at time $T$. Note that $\theta_{d i / T}=1$ means the suspicious faulty equipment corresponding to $D_{i}$ faults and vice versa.

(ii) $T$ is the sequence time of spikes, and a $\mathrm{DN}$ produces a spike at each unit time. Thus, a pulse value sequence is formed and recorded in the DN after $T$ unit time.

(iii) $f_{i}$ is a forgetting rule of the $i$-th $\mathrm{DN}$ with the form $E /\left\{a^{\theta_{\text {dilT }}} \longrightarrow \lambda ; g=0\right\}$, where $g$ represents the reasoning step of the reasoning algorithm of the srSNPS, i.e., the selfupdating matrix reasoning algorithm proposed in the next subsection. It means that if $f_{i}$ is applied, then spikes in the $D_{i}$ are emptied and the calculation process will be reinitialized (i.e., $g=0$ ). The firing condition is $E=\left\{\theta_{d i / T}^{\prime} \neq \theta_{d i / T}\right\}$, representing that the pulse value in $D_{i}$ has changed.

(b) $C_{j}=\left(\theta_{c j / T}, T, f_{j}, A_{r j}\right), 1 \leq j \leq t$, is the $j$-th condition neuron $(\mathrm{CN})$ in $M_{e}$ and represents a protective relay or circuit breaker in the targeted power transmission network, where

(i) $\theta_{c j / T}$ equals to 0 or 1 representing the pulse value of the $j$-th $\mathrm{CN}$ at time $T$. Note that $\theta_{c j / T}=1$ means the protection device corresponding to $C_{j}$ has acted and vice versa.

(ii) $T$ is the sequence time of spikes, and a $\mathrm{CN}$ produces a spike at each unit time. Thus, a pulse value sequence is formed and recorded in the $\mathrm{CN}$ after $T$ unit time.

(iii) $f_{j}$ is a forgetting rule of the $j$-th $\mathrm{CN}$ with the form $E /\left\{a^{\theta_{c j / T}} \longrightarrow \lambda ; g=0\right\}$. It means that if $f_{j}$ is applied, then spikes in $C_{j}$ are emptied and the calculation process will be reinitialized (i.e., $g=0$ ). The firing condition is $E=\left\{\theta_{c j / T}^{\prime} \neq \theta_{c j / T}\right\}$, representing that the pulse value in $C_{j}$ has changed.

(c) $A_{r j}$ represents an apoptosis rule in $M_{e}$ with the form $E /\left\{C_{j}\right\} \longrightarrow\left\{\right.$ Algorithm $\left.1^{\{L\}}\right\}$, which means that if $A_{r j}$ is applied, then $C_{j}$ executes its apoptosis rule to determine whether it lives or dies. That is, CNs execute Algorithm 1 to output survival condition neuron (containing important information) set $L$. In the same time, CNs including redundant information die and will not participate in fault reasoning. The firing condition is $E=\left\{g=0 \cap \operatorname{sig}_{j}=0\right\}$ indicating that the rule $A_{r j}$ can be applied if and only if in the initial configuration [43] (that is, $g=0$ ) with $\operatorname{sig}_{j}=0$ (please see Definition 2).

(3) $\sigma_{i}=\left(\theta_{i}, r_{i}, e_{i}\right), 1 \leq i \leq p$, is the $i$-th proposition neuron $(\mathrm{PN})$ corresponding to a protection device or the equipment, $\sigma_{j}=\left(\delta_{j}, r_{j}\right), 1 \leq j \leq q$, is the $j$-th rule neuron (RN) corresponding to a fault production rule, and $p+q=m$, where

(a) $\theta_{i}$ and $\delta_{j}$ are pulse values (equal to 0 or 1 ) in proposition neuron $\sigma_{i}$ and rule neuron $\sigma_{j}$, respectively.

(b) $r_{i}$ represents a firing rule of $\sigma_{i}$ with the form $E / a^{\theta} \longrightarrow a^{\theta}$, where $E=\{a\}$ is the firing condition, which means that once $\sigma_{i}$ contains a spike, $r_{i}$ can be applied. Then, $\sigma_{i}$ will consume a spike with pulse value $\theta$, produce a new spike with the same pulse value, and then transmit it to its postsynaptic neurons; $r_{j}$ represents a firing rule of $\sigma_{j}$ with the form $E / a^{\delta} \longrightarrow a^{\beta}$, where $E=\{a\}$ is the firing condition, which means that once $\sigma_{j}$ contains a spike, $r_{j}$ can be applied. Then, $\sigma_{j}$ will consume a spike with pulse value $\delta$, produce a new spike with pulse value $\beta$ (equals to 0 or 1 ), and then transmit it to its postsynaptic neurons.

(c) $e_{i}$ represents a self-updating rule of the form $E / a^{\theta} \longrightarrow a^{\bar{\theta}}$. The firing condition is $E=\left\{\varepsilon_{i}>0\right\}$, which means that $e_{i}$ can be applied if and only if the self-updating operator $\varepsilon_{i}>0$. Then, $\sigma_{i}$ will consume a spike with pulse value $\theta$, produce a new spike with pulse value $\bar{\theta}$ (equals to 0 or 1 , called the antispike of $\theta$ ), and then $\varepsilon_{i}=\varepsilon_{i}-1$. Note that only input proposition neurons contain self-updating rules.

(4) syn $\subseteq\{1, \ldots, m\} \times\{1, \ldots, m\}$ with $i \neq j$ for all $(i, j) \in$ syn for $1 \leq i, j \leq m$ is a directed synaptic connection between linked neurons.

(5) in, out indicate the input neuron set and output neuron set, respectively.

Note that if a $\mathrm{PN}$ is an input neuron, then it corresponds to a protection device, i.e., a protective relay or a circuit breaker. In this case, the pulse value in $\sigma_{i}$ represents the action information of its corresponding protection device, where $\theta_{i}=1$ means that the device has acted, while $\theta_{i}=0$ means it does not. If a $\mathrm{PN}$ is an output neuron, then it corresponds to suspicious faulty equipment. In this case, $\theta_{i}=$ 1 indicates that the equipment is faulty, and $\theta_{i}=0$ means it is not.

Definition 2. The importance degree of $C_{j}(1 \leq j \leq t)$ is

$$
\operatorname{sig}\left(C_{j}\right)=I\left(C_{j}, D\right)=h\left(C-C_{j}\right)-h(C),
$$

where $h\left(C-C_{j}\right)$ is the conditional information entropy (CIE) of the other condition neurons to decision-making neurons after $C_{j}$ dies.

Definition 3. The CIE of a condition neuron $C$ is

$$
h(C)=-\sum_{i=1}^{|U / C|} p\left(X_{i}\right) \sum_{j=1}^{|U / D|} p\left(Y_{j} \mid X_{i}\right) \log p\left(Y_{j} \mid X_{i}\right),
$$

where $U$ is called the universe, $D$ is a $\mathrm{DN}, p\left(X_{i}\right)$ represents the probability of $X_{i}$ on $U$, and $p\left(Y_{j} \mid X_{i}\right)=\left|Y_{j} \cap X_{i}\right| / X_{i}$ 
indicates the probability of the event $Y_{j}$ under the occurrence event $X_{i}$.

Definition 4. $M_{e}$ of neurons in an srSNPS is a knowledge base $K=(U, R)$, where $R$ is a nonempty finite set of attributes. Set $X=\left\{X_{1}, X_{2}, \ldots, X_{n}\right\}$ and $Y=\left\{Y_{1}, Y_{2}, \ldots, Y_{m}\right\}$ as the partitions of $P$ and $Q$ on $U$, respectively. The probability distributions of $P$ and $Q$ on the $\sigma$ algebra composed of subsets of $U$ are

$$
\begin{aligned}
& {[X: p]=\left[\begin{array}{cccc}
X_{1} & X_{2} & \cdots & X_{n} \\
p\left(X_{1}\right) & p\left(X_{2}\right) & \cdots & p\left(X_{n}\right)
\end{array}\right],} \\
& {[Y: p]=\left[\begin{array}{cccc}
Y_{1} & Y_{2} & \cdots & Y_{m} \\
p\left(Y_{1}\right) & p\left(Y_{2}\right) & \cdots & p\left(Y_{m}\right)
\end{array}\right],}
\end{aligned}
$$

where $p\left(X_{i}\right)=\left|X_{i}\right| /|U|, i=1, \ldots, n$ and $p\left(Y_{j}\right)=\left|Y_{j}\right| /|U|$, $j=1, \ldots, m$.

Algorithm 1 used in the apoptosis rule is the apoptosis algorithm for condition neurons, described as follows. Its output is a survival condition neuron set $L$. The neurons in $L$ will be connected according to the synaptic connection rule in Definition 5.

Definition 5. Synaptic connection rules in this study are (1) read the information sequences of DNs and survival CNs to form the minimum reduction decision table (MRDT); (2) create a fault production rule set (FPRS) for the MRDT; and (3) realize synaptic connection according to production rules in the FPRS. Note that only the living neurons (including DNs and survival CNs) can build synapses. The dead condition neurons are unable to establish any effective synapses.

To improve the intelligibility, a sketch map of neurons and the microenvironment are shown in Figure 1, and a diagram of evolutionary process of an srSNPS is shown in Figure 2, where the ODT represents the original decision table of a fault to be diagnosed. In an srSNPS, there are three types of rule neurons, i.e., General-, And-, and Or-rule neurons. All of them can represent fault production rules but with different processing methods of spikes, which will be described in detail in Section 2.2.

2.2. Self-Updating Matrix Reasoning Algorithm. To explain the SMRA, we first introduce its vectors, matrices, and operators as follows:

(1) $\boldsymbol{\theta}=\left(\theta_{1}, \ldots, \theta_{p}\right)^{T}$ is a pulse value vector of PNs, where $\theta_{i}(1 \leq i \leq p)$ represents the pulse value of $i$-th PN $\sigma_{i}$. If $\sigma_{i}$ is an input neuron, then $\theta_{i}=1$ means the protection device associated with $\sigma_{i}$ has acted, and $\theta_{i}=0$ means it has not acted. If $\sigma_{i}$ is an output neuron, then $\theta_{i}=1$ means the corresponding suspicious equipment is faulty, and $\theta_{i}=0$ means it is not faulty.

(2) $\boldsymbol{\delta}=\left(\delta_{1}, \ldots, \delta_{q}\right)^{T}$ is a pulse value vector of $\mathrm{RNs}$, where $\delta_{j}(1 \leq j \leq q)$ is the pulse value of the $j$-th RN.

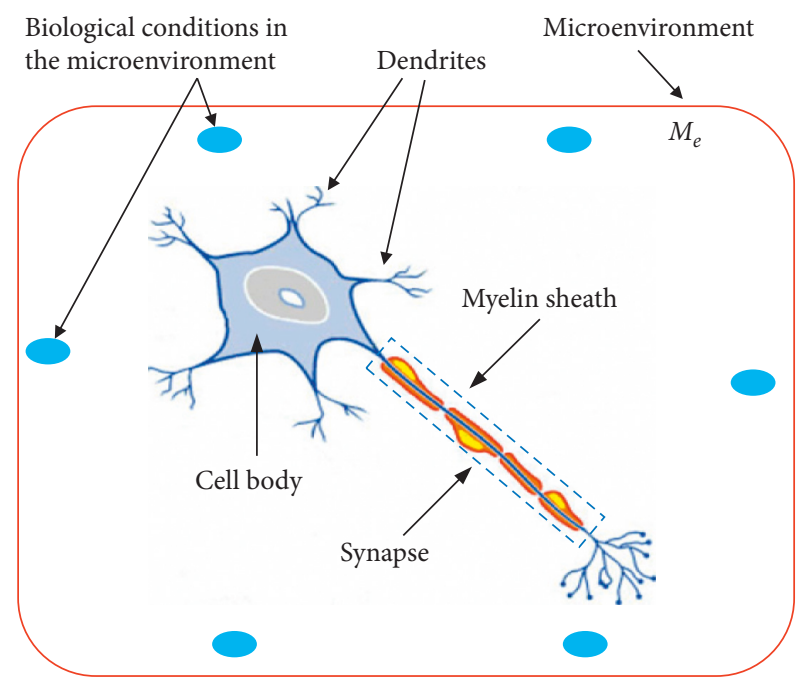

FIGURE 1: Sketch map of neurons and microenvironment.

(3) $\boldsymbol{\varepsilon}=\left(\varepsilon_{1}, \ldots, \varepsilon_{l}\right)^{T}(1 \leq l \leq p)$ is a self-updating operator vector of input neurons, where $\varepsilon_{i}(1 \leq i \leq l)$ is the self-updating operator of the $i$-th input neuron.

(4) $\mathbf{D}_{1}=\left(d_{i j}\right)_{p \times q}$ is a synaptic matrix, which represents the directed synaptic connection from PNs to general RNs. If there is a synapse from $\mathrm{PN} \sigma_{i}$ to general RN $\sigma_{j}$, then $d_{i j}=1$; otherwise, $d_{i j}=0$.

(5) $\mathbf{D}_{2}=\left(d_{i j}\right)_{p \times q}$ is a synaptic matrix, which represents the directed synaptic connection from PNs to And RNs. If there is a synapse from $\mathrm{PN} \sigma_{i}$ to $A n d \mathrm{RN} \sigma_{j}$, then $d_{i j}=1$; otherwise, $d_{i j}=0$.

(6) $\mathbf{D}_{3}=\left(d_{i j}\right)_{p \times q}$ is a synaptic matrix, which represents the directed synaptic connection from PNs to $\mathrm{Or}$ RNs. If there is a synapse from PNs $\sigma_{i}$ to $\operatorname{Or} \mathrm{RN} \sigma_{j}$, then $d_{i j}=1$; otherwise, $d_{i j}=0$.

(7) $\mathbf{E}=\left(e_{j i}\right)_{q \times p}$ is a synaptic matrix, which represents the directed synaptic connection from RNs to PNs. If there is a synapse from RN $\sigma_{j}$ to $\mathrm{PN} \sigma_{i}$, then $e_{j i}=1$; otherwise, $e_{j i}=0$.

(8) $\mathbf{D}^{T} \otimes \boldsymbol{\theta}=\left(\bar{d}_{1}, \ldots, \bar{d}_{q}\right)$, where $\quad \bar{d}_{j}=d_{1 j} \times \theta_{1}+$ $\ldots+d_{s j} \times \theta_{q}, j=1, \ldots, q$.

(9) $\mathbf{D}^{T} \cdot \boldsymbol{\theta}=\left(\bar{d}_{1}, \ldots, \bar{d}_{q}\right)$, where $\bar{d}_{j}=\min \left(d_{1 j} \times \theta_{1}\right.$, $\left.\ldots, d_{q j} \times \theta_{q}\right), j=1, \ldots, q$.

(10) $\mathbf{D}^{T} \circ \boldsymbol{\theta}=\left(\bar{d}_{1}, \ldots, \bar{d}_{q}\right)$, where $\bar{d}_{j}=\max \left(d_{1 j} \times \theta_{1}\right.$, $\left.\ldots, d_{p j} \times \theta_{p}\right), j=1, \ldots, q$. Likewise, $\mathbf{E}^{T} \circ \boldsymbol{\theta}=\left(\bar{e}_{1}\right.$, $\left.\ldots, \bar{e}_{p}\right)$, where $\bar{e}_{i}=\max \left(e_{1 j} \times \theta_{1}, d_{2 j} \times \theta_{2}, \ldots\right.$, $\left.d_{q i} \times \theta_{q}\right), i=1, \ldots, p$.

To parallelly reason and calculate fault alarm messages, we design the SMRA for srSNPSs as follows.

\section{The Proposed Methodology}

This section proposes a fault diagnosis method for power transmission networks based on the srSNPS, whose flowchart is shown in Figure 3 and described as follows:

Step 1: transmission network partition. 


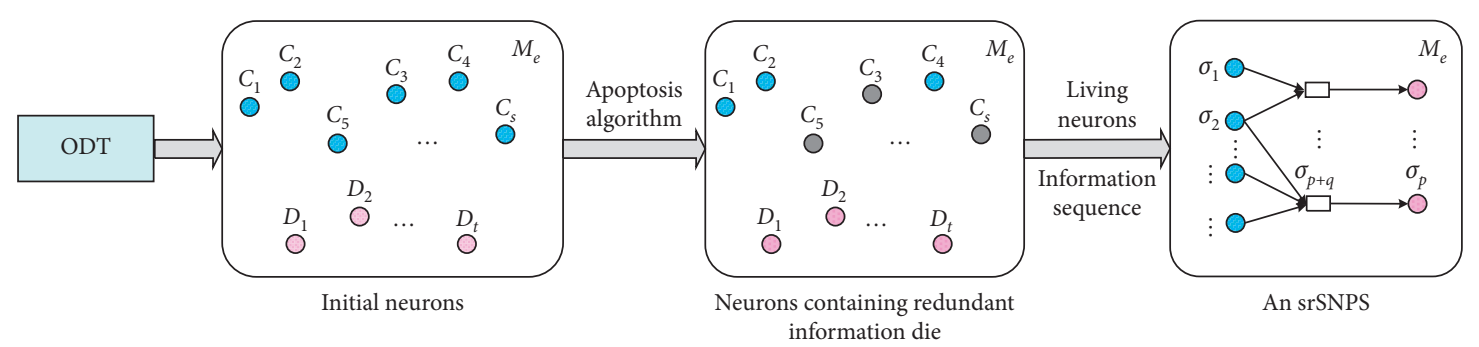

Figure 2: Diagram of evolutionary process of an srSNPS.

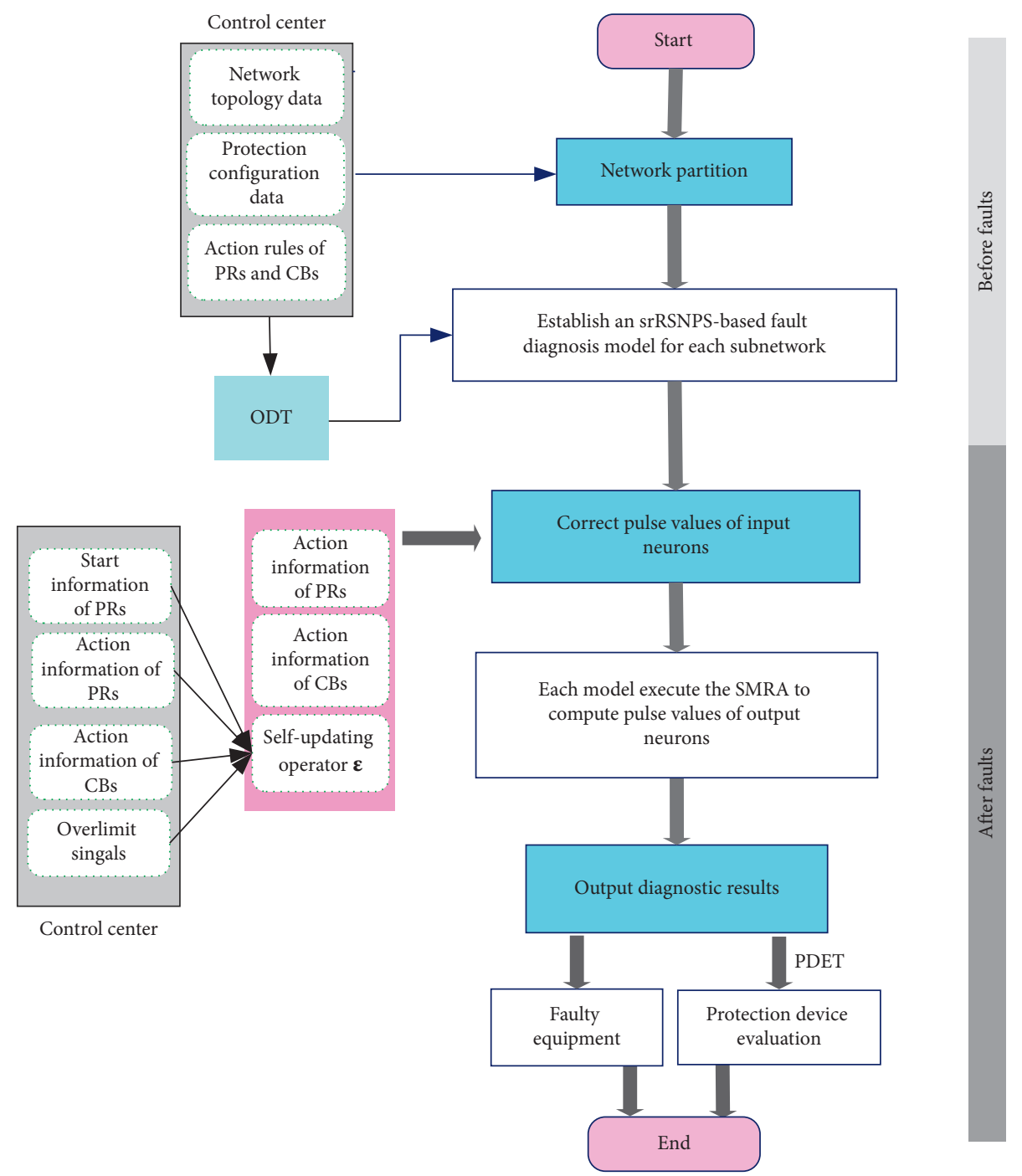

FIgURE 3: Flowchart of the proposed srSNPS-based fault diagnosis method.

(a) Generate the Depth-First Search Tree (DST). Employ the depth-first search algorithm $[60,61]$ to simplify the numbered transmission network to generate the corresponding DST, in which nodes represent buses.

(b) Divide the DST. Use the weight network segmentation method $[60,61]$ to split the DST while ensuring that the computational burden of each subnetwork after network partition is approximately the same.

Step 2: establish an srSNPS-based fault diagnosis model for each subnetwork. The subnetworks perform the following steps (a)-(d) in a parallel way:

(a) Select Living Neurons. (i) Transport the ODT of the fault into the microenvironment, i.e., feed 
conditional attributes of the ODT into CNs in $M_{e}$ and decision-making attributes into DN neurons. (ii) CNs execute apoptosis rules (i.e., Algorithm 1) to select survival ones. The purpose of this step is to select out important fault alarm messages (i.e., the core attribute fault information) by deleting redundant ones.

(b) Establish MRDT. Read the information sequences of DNs and survival CNs to form the MRDT.

(c) Create the FPRS via the obtained MRDT.

(d) Realize Synaptic Connections to Build an srSNPSBased Model for Each Subnetwork. Establish synapses according to Definition 5. Note that each fault production rule corresponds to a rule neuron, while each antecedent or consequent proposition in a rule is associated with a proposition neuron. Now, the survival CNs mutate to input PNs and the DNs mutate to output PNs. The pulse values in the input PNs represent the core attribute fault information (corresponding to action information of PRs or CBs) in fault alarm messages.

Step 3: correct pulse values of input neurons. Integratedly utilize the start information and action information of protection devices based on the fault information matrix (please see Subsection 3.1) to get the self-updating operator vector of input neurons, i.e., $\boldsymbol{\varepsilon}$. Then, each input neuron applies its self-updating rule to correct and update its pulse value. Accordingly, the wrong action information of protection devices is corrected because the pulse value of each input neuron represents the action information of a protective relay or a circuit breaker. The flowchart of this step is shown in Figure 4.

Step 4: compute pulse values of output neurons. Each subnetwork performs the SMRA (i.e., Algorithm 2) of its srSNPS-based fault diagnosis model in a parallel way to reasoning out the pulse values of output neurons.

Step 5: output diagnosis results. If and only if the pulse value of an output neuron is 1 , its corresponding equipment is faulty.

Step 6: evaluate uncertain behaviors of protection devices. Search the protection device event tree (PDET, please see Subsection 3.2) to find the false or lost alarm messages of protection devices.

The purpose of Step 1 includes (a) simplify decisionmaking samples for srSNPS-based diagnosis models. The typical fault diagnosis methods based on rough sets establish the ODT of a fault event via the fault data of the entire transmission network, while our proposed method concurrently establishes the ODT for each subnetwork; (b) improve the topological adaptability of networks. When the topology of a transmission network changes, it just needs to modify the srSNPS-based diagnosis model of the corresponding subnetwork. Besides, Steps 1 and 2 are finished

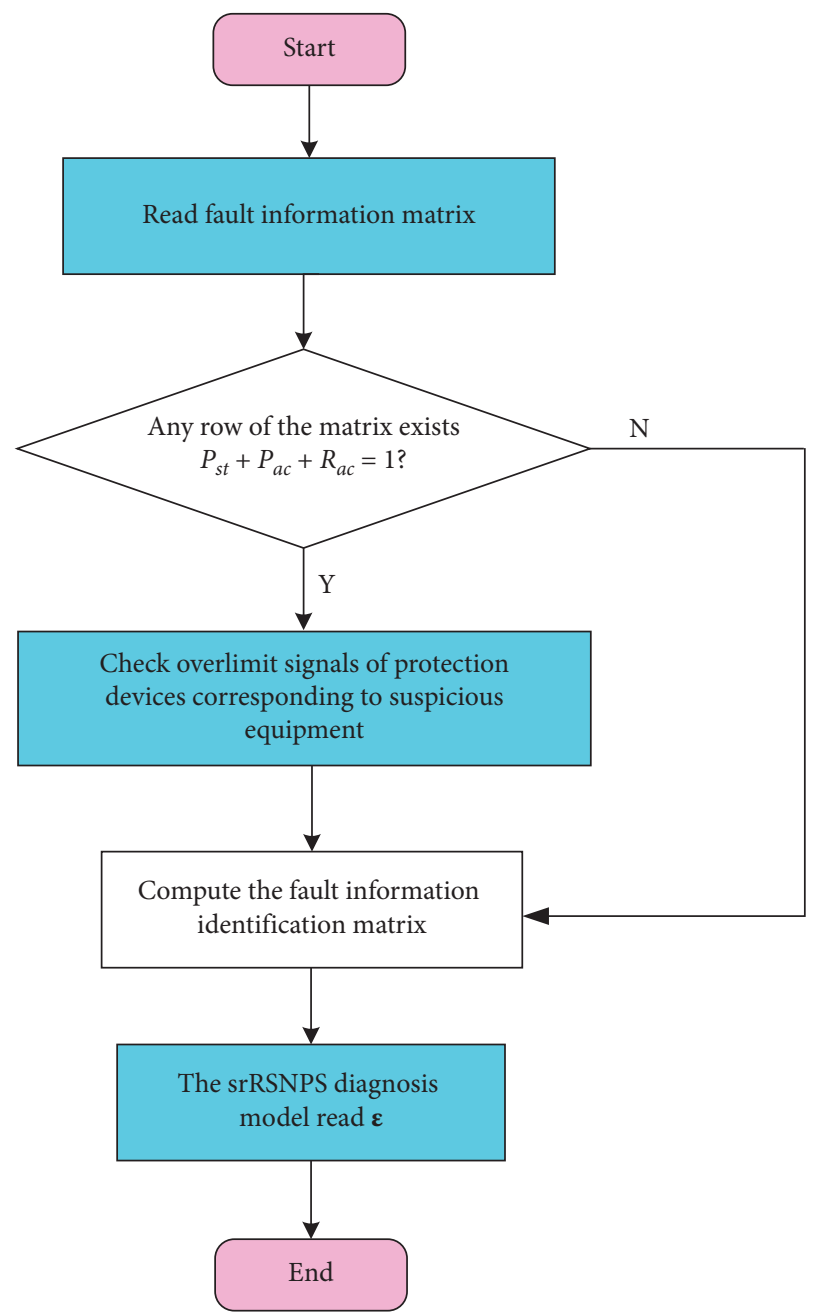

FIGURE 4: Flowchart of correction steps for action information.

before faults occur, and Steps 3-6 are executed immediately after failures. Thus, the proposed method can save some time.

3.1. Correct Pulse Values of Input Neurons in srSNPS-Based Diagnosis Models. Define the fault information matrix of a $\mathrm{CB}$ (labeled as A) as

$$
M_{A}=\left[\begin{array}{lll}
P_{s t A}^{(1)} & P_{a c A}^{(1)} & R_{a c A} \\
P_{s t A}^{(2)} & P_{a c A}^{(2)} & R_{a c A} \\
P_{s t A}^{(3)} & P_{a c A}^{(3)} & R_{a c A} \\
P_{s t A}^{(4)} & P_{a c A}^{(4)} & R_{a c A}
\end{array}\right],
$$

where $P_{s t A}^{(u)}$ is the start information of PRs, $P_{a c A}^{(u)}$ is the action information of PRs, and $u=1,2,3,4$ represents the main protective, first backup protective, second backup protective, and bus protective relays associated with the $\mathrm{CB}$, respectively; $R_{a c A}$ is the action information of the CB. Particularly, if there is no bus PR, $P_{s t A}^{(4)}=P_{a c A}^{(4)}=0$. 
Define the fault information identification matrix $N_{A}$ as

$$
N_{A}=\left[\begin{array}{cc}
P_{j A}^{(1)} & R_{j A} \\
P_{j A}^{(2)} & R_{j A} \\
P_{j A}^{(3)} & R_{j A} \\
P_{j A}^{(4)} & R_{j A}
\end{array}\right],
$$

where $P_{j A}^{(u)} \quad\left(P_{j A}^{(u)}=P_{s t A}^{(u)} \oplus P_{a c A}^{(u)}, u=1,2,3,4\right)$ represents decision value of status for the corresponding $\mathrm{PR}$ and $\oplus$ is the xor operation. When $P_{j A}^{(u)}=1$, read overlimit signals of protection devices corresponding to the suspicious equipment.

$\boldsymbol{\varepsilon}=\left(\varepsilon_{1}, \ldots, \varepsilon_{l}\right)^{T}$ is the self-updating operator vector of input neurons. Define $\varepsilon_{i}(1 \leq i \leq l)$ as

$$
\varepsilon_{i}= \begin{cases}\frac{0}{0}, & \bigcup_{z=1}^{4}\left(P_{s t i}^{(z)}+P_{a c i}^{(z)}\right)=0, \\ \frac{0}{\left(P_{j i}^{(3)} \oplus R_{j i}\right) \cup\left(P_{j i}^{(4)} \oplus R_{j i}\right)}, & \bigcup_{z=1}^{2}\left(P_{s t i}^{(z)}+P_{a c i}^{(z)}\right)=0, \\ \frac{\left(P_{j i}^{(1)} \oplus R_{j i}\right) \cup\left(P_{j i}^{(2)} \oplus R_{j i}\right)}{0}, & \bigcup_{z=3}^{4}\left(P_{s t i}^{(z)}+P_{a c i}^{(z)}\right)=0, \\ \frac{\left(P_{s t i}^{(1)} \oplus R_{j i}\right) \cup\left(P_{j i}^{(2)} \oplus R_{j i}\right)}{\left(P_{j i}^{(3)} \oplus R_{j i}\right) \cup\left(P_{j i}^{(4)} \oplus R_{j i}\right)}, & \bigcup_{z=1}^{4}\left(P_{s t i}^{(z)}+P_{a c i}^{(z)}\right) \neq 0,\end{cases}
$$

where the symbol "-_" is not the fraction line. The symbols above "-" indicate self-updating operators of lines where protective devices associated with input neurons are located, while the ones under "-" represent self-updating operators of buses.

3.2. Search the Protection Device Event Tree. According to start and action messages of PRs, action messages of CBs, and overlimit signals of faulty equipment, the PDET for a fault event is generated as shown in Figure 5, where $P_{s t i}$ and $P_{a c i}$ are the start and action information of the $i$-th PR, respectively, $R_{a c i}$ is the action information of the corresponding $\mathrm{CB}$, and $\mathrm{OL}_{i}$ is the overlimit signal of the faulty equipment we have found; the start and action messages are represented by 0 , the overlimit signals are indicated by $\square$, and the behaviors of protection devices are represented by $\diamond$; the pink in above symbol represents the corresponding protection device has acted, while the gray color means it does not. When faulty equipment is got in Section 3-Step 5, then we search the PDET to evaluate uncertain behaviors of protection devices.

\section{Case Study}

The proposed method is applied to the IEEE 14-bus and IEEE 118-bus systems to demonstrate its effectiveness and superiority.

4.1. IEEE 14-Bus System. There are 14 buses, 20 lines, 40 circuit breakers, 40 line main protective relays, 40 line first backup protective relays, 40 line second backup protective relays, and 14-bus protective relays.

4.1.1. Comparative Tests. Ten cases including uncertainty and incompleteness, such as maloperation and misinformation, are used to do the comparisons between the proposed method and three typical fault diagnosis methods, i.e., the cause-effect network (CEN) in [2], the fuzzy Petri net (FPN) in [18], and the fuzzy reasoning spiking neural $\mathrm{P}$ system (FRSNPS) in [36]. The reason choosing the three methods is that their performance over many other approaches has been demonstrated. The diagnosis results are shown in Table 1.

For cases 1 and 2, four methods can find the right faulty equipment. Therefore, they are all effective without uncertain or incomplete fault information. For case 3, only the proposed method and the FRSNPS are successful, while both CEN and FPN are failed. For cases 4-7, only our method can accurately diagnose the faults. Cases $8-10$ are three extreme examples, i.e., all the action information of protective relays or circuit breakers are lost. The CEN, FPN, and FRSNPS are all failed for cases $8-10$, while our method is successful for cases 8 and 9 and failed for the case 10. This is because the lost information in cases 8 and 9 is the redundant information in our method, and the one in case 10 is the core attribute information. Therefore, we can see that if the uncertainty and incompleteness occur in the redundant information, it has no effect on the diagnosis results of the proposed method. However, when it happens in the core attribute information, it will influence the results. Fortunately, due to the stability of the relay protection system, the case of complete loss of all core attribute information is very rare under normal operation of power systems. Therefore, Table 1 shows that the proposed method can obtain satisfying results in the situations with incomplete or uncertain alarm information for both single and multiple faults.

Besides, the computational complexities of the CEN, FPN, and FRSNPS are analyzed. Note that the computational complexities of the four methods are all in the linear order. Since the proposed method reduces redundant information by the apoptosis algorithm of condition neurons, the number of neurons used for establishing srSNPS-based fault diagnosis models is smaller than that of the CEN, FPN, and FRSNPS. The more the redundant information, the smaller the computational complexity of the proposed method. In a fault diagnosis problem, there is typically much redundant information. So, the upper limit of algorithm computational complexity for the proposed method is far less than that of the other three methods. Therefore, we can see that, although our method needs more information (such as start information and overlimit signals) to improve its diagnostic accuracy, the time complexity does not increase.

4.1.2. Disturbed Tests. To verify the fault-tolerant ability of our method, we take the disturbed test under different uncertain information ratios (UIRs). The test results are shown in Table 2.

Define the UIR as 


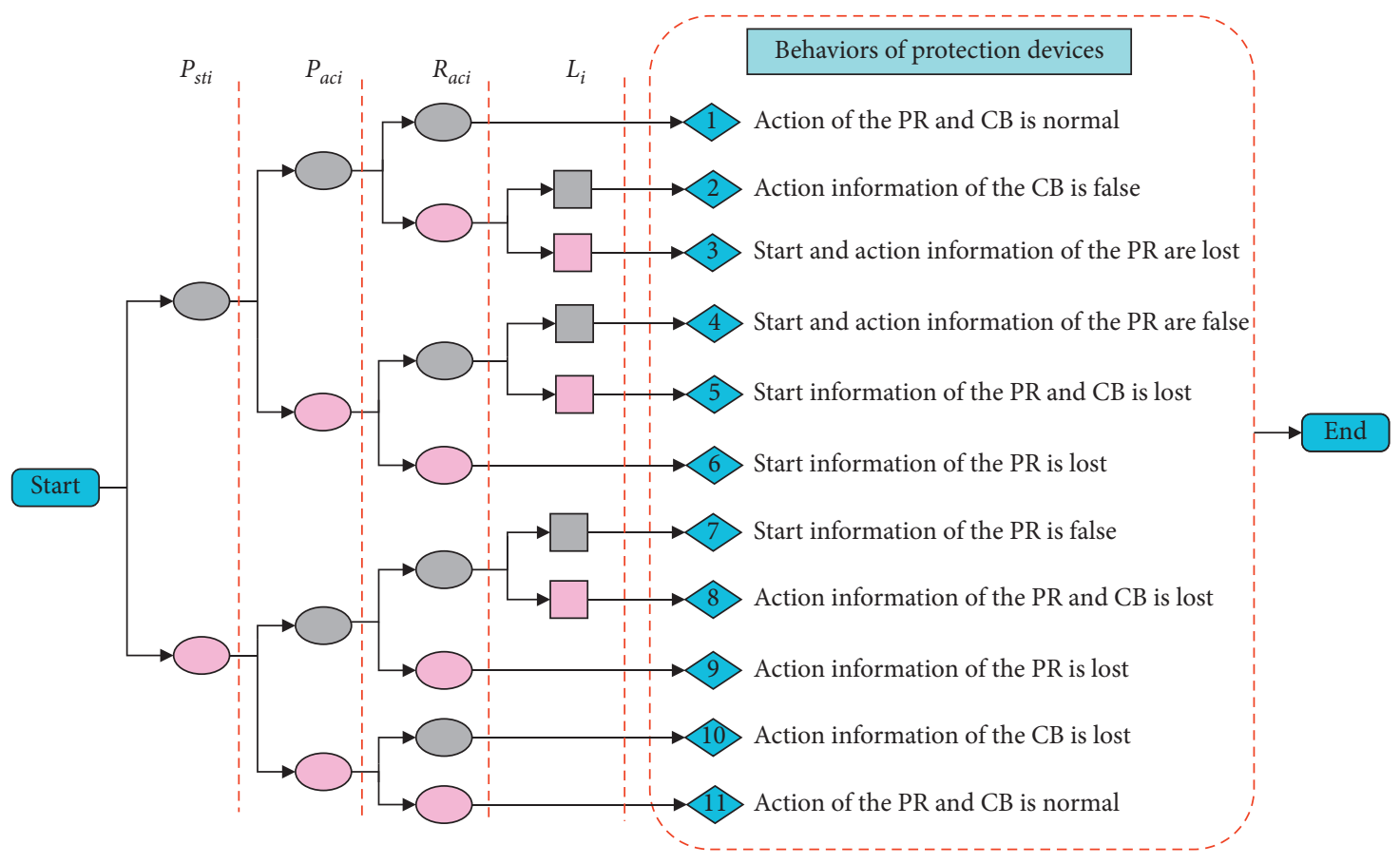

FIgURE 5: Protection device event tree.

TABLE 1: Comparisons of diagnosis results between the proposed method and three typical fault diagnosis methods for the 14-bus system.

\begin{tabular}{|c|c|c|c|c|c|c|c|c|}
\hline \multirow{3}{*}{ Cases } & \multicolumn{4}{|c|}{ Preset faults } & \multirow{3}{*}{$\begin{array}{l}\text { FPN } \\
{[18]}\end{array}$} & \multirow{3}{*}{$\begin{array}{c}\text { FRSNPS } \\
{[36]}\end{array}$} & \multicolumn{2}{|r|}{ The proposed method } \\
\hline & \multicolumn{2}{|c|}{$\begin{array}{l}\text { Action } \\
\text { information of } \\
\text { protection } \\
\text { devises }\end{array}$} & \multirow[t]{2}{*}{$\begin{array}{c}\text { Faulty } \\
\text { equipment }\end{array}$} & \multirow[t]{2}{*}{$\begin{array}{c}\text { CEN } \\
{[2]}\end{array}$} & & & \multirow[t]{2}{*}{$\begin{array}{l}\text { Diagnosis } \\
\text { results }\end{array}$} & \multirow[t]{2}{*}{ Information evaluation } \\
\hline & PRs & CBs & & & & & & \\
\hline 1 & $\begin{array}{l}\operatorname{MLR}_{1314} \\
\operatorname{MLR}_{1413}\end{array}$ & $\begin{array}{l}\mathrm{CB}_{1314} \\
\mathrm{CB}_{1413} \\
\end{array}$ & $\mathrm{~L}_{1314}$ & $\mathrm{~L}_{1314}$ & $\mathrm{~L}_{1314}$ & $\mathrm{~L}_{1314}$ & $\mathrm{~L}_{1314}$ & Correct action \\
\hline 2 & $\begin{array}{l}\mathrm{MLR}_{1314} \\
\mathrm{MLR}_{1413} \\
\mathrm{SLR}_{0613} \\
\mathrm{SLR}_{1213} \\
\end{array}$ & $\begin{array}{l}\mathrm{CB}_{1213} \\
\mathrm{CB}_{0613} \\
\mathrm{CB}_{1413} \\
\mathrm{CB}_{1314} \\
\end{array}$ & $\begin{array}{c}\mathrm{L}_{1314} \\
\mathrm{~B}_{13}\end{array}$ & $\begin{array}{c}\mathrm{L}_{1314} \\
\mathrm{~B}_{13}\end{array}$ & $\begin{array}{c}\mathrm{L}_{1314} \\
\mathrm{~B}_{13}\end{array}$ & $\begin{array}{c}\mathrm{L}_{1314} \\
\mathrm{~B}_{13}\end{array}$ & $\begin{array}{c}\mathrm{L}_{1314} \\
\mathrm{~B}_{13}\end{array}$ & Correct action \\
\hline 3 & $\begin{array}{c}\mathrm{BR}_{12} \\
\mathrm{ML}_{1213} \\
\mathrm{ML}_{1314} \\
\end{array}$ & $\begin{array}{l}\mathrm{CB}_{1312} \\
\mathrm{CB}_{1206}\end{array}$ & $\begin{array}{c}\mathrm{L}_{1213} \\
\mathrm{~B}_{12}\end{array}$ & $\begin{array}{c}\mathrm{L}_{1213} \\
\mathrm{~B}_{12}\end{array}$ & $\begin{array}{c}\mathrm{L}_{1213} \\
\mathrm{~B}_{12}\end{array}$ & $\begin{array}{c}\mathrm{L}_{1213} \\
\mathrm{~B}_{12}\end{array}$ & $\begin{array}{c}\mathrm{L}_{1213} \\
\mathrm{~B}_{12}\end{array}$ & Lost information: $\mathrm{CB}_{1213}$ \\
\hline 4 & $\begin{array}{c}\mathrm{BR}_{13} \\
\mathrm{MLR}_{1213}\end{array}$ & $\begin{array}{l}\mathrm{CB}_{1213} \\
\mathrm{CB}_{1312} \\
\end{array}$ & $\begin{array}{c}\mathrm{L}_{1213} \\
\mathrm{~B}_{13} \\
\end{array}$ & $\begin{array}{c}\mathrm{L}_{1213} \\
\mathrm{~B}_{13} \\
\end{array}$ & $\mathrm{~L}_{1213}$ & $\begin{array}{c}\mathrm{L}_{1213} \\
\mathrm{~B}_{13} \\
\end{array}$ & $\begin{array}{c}\mathrm{L}_{1213} \\
\mathrm{~B}_{13} \\
\end{array}$ & Lost information: $\mathrm{BLR}_{1312}, \mathrm{CB}_{1306}, \mathrm{CB}_{1314}$ \\
\hline 5 & $\begin{array}{l}\operatorname{MLR}_{1213} \\
\operatorname{MLR}_{1312} \\
\operatorname{SLR}_{1206} \\
\end{array}$ & $\mathrm{CB}_{0612}$ & $\begin{array}{c}\mathrm{L}_{1213} \\
\mathrm{~B}_{12}\end{array}$ & $\mathrm{~L}_{1213}$ & $\mathrm{~L}_{1213}$ & $\begin{array}{c}\mathrm{L}_{1213} \\
\mathrm{~B}_{12}\end{array}$ & $\begin{array}{c}\mathrm{L}_{1213} \\
\mathrm{~B}_{12}\end{array}$ & Lost information: $\mathrm{CB}_{1312}, \mathrm{CB}_{1213}, \mathrm{SLR}_{1312}$ \\
\hline 6 & $\begin{array}{c}\mathrm{BR}_{12} \\
\mathrm{BR}_{13} \\
\mathrm{SLR}_{1312} \\
\mathrm{SLR}_{1306}\end{array}$ & $\begin{array}{l}\mathrm{CB}_{1206} \\
\mathrm{CB}_{1213} \\
\mathrm{CB}_{1312} \\
\mathrm{CB}_{1314} \\
\mathrm{CB}_{1409} \\
\mathrm{CB}_{1306} \\
\end{array}$ & $\begin{array}{c}\mathrm{B}_{12} \\
\mathrm{~L}_{1314}\end{array}$ & $\begin{array}{c}\mathrm{B}_{12} \\
\mathrm{~B}_{13} \\
\mathrm{~L}_{1314}\end{array}$ & $\begin{array}{c}\mathrm{B}_{12} \\
\mathrm{~B}_{13} \\
\mathrm{~L}_{1314}\end{array}$ & $\begin{array}{c}\mathrm{B}_{12} \\
\mathrm{~B}_{13} \\
\mathrm{~L}_{1314}\end{array}$ & $\begin{array}{c}\mathrm{B}_{12} \\
\mathrm{~L}_{1314}\end{array}$ & $\begin{array}{l}\text { False information: } \mathrm{BR}_{13}, \mathrm{CB}_{1312}, \mathrm{CB}_{1314} \\
\text { Lost information: } \mathrm{SLR}_{1409}\end{array}$ \\
\hline 7 & $\begin{array}{c}\mathrm{BR}_{12} \\
\mathrm{MLR}_{1314} \\
\mathrm{MLR}_{1413}\end{array}$ & $\begin{array}{l}\mathrm{CB}_{1213} \\
\mathrm{CB}_{1206} \\
\mathrm{CB}_{1306} \\
\mathrm{CB}_{1314} \\
\mathrm{CB}_{1413} \\
\end{array}$ & $\begin{array}{c}\mathrm{B}_{12} \\
\mathrm{~B}_{13} \\
\mathrm{~L}_{1314}\end{array}$ & $\begin{array}{c}\mathrm{B}_{12} \\
\mathrm{~L}_{1314}\end{array}$ & $\begin{array}{c}\mathrm{B}_{12} \\
\mathrm{~L}_{1314}\end{array}$ & $\begin{array}{c}\mathrm{B}_{12} \\
\mathrm{~L}_{1314}\end{array}$ & $\begin{array}{c}\mathrm{B}_{12} \\
\mathrm{~B}_{13} \\
\mathrm{~L}_{1314}\end{array}$ & Lost information: $\mathrm{BR}_{13}, \mathrm{CB}_{1312}$ \\
\hline
\end{tabular}


TABLE 1: Continued.

\begin{tabular}{|c|c|c|c|c|c|c|c|c|}
\hline \multirow{3}{*}{ Cases } & \multicolumn{3}{|c|}{ Preset faults } & \multirow{3}{*}{$\begin{array}{c}\text { CEN } \\
{[2]}\end{array}$} & \multirow{3}{*}{$\begin{array}{r}\text { FPN } \\
{[18]}\end{array}$} & \multirow{3}{*}{$\begin{array}{c}\text { FRSNPS } \\
{[36]}\end{array}$} & \multirow{3}{*}{$\begin{array}{l}\text { Diagnosis } \\
\text { results }\end{array}$} & \multirow{3}{*}{$\begin{array}{l}\text { The proposed method } \\
\text { Information evaluation }\end{array}$} \\
\hline & $\begin{array}{r}\mathrm{Ac} \\
\text { inform } \\
\text { prot } \\
\mathrm{de}\end{array}$ & $\begin{array}{l}\text { on } \\
\text { tion of } \\
\text { ction } \\
\text { ses }\end{array}$ & $\begin{array}{c}\text { Faulty } \\
\text { equipment }\end{array}$ & & & & & \\
\hline & PRs & CBs & & & & & & \\
\hline 8 & - & $\mathrm{CB}_{1312}$ & $\mathrm{~B}_{12}$ & $\begin{array}{c}\text { No } \\
\text { fault }\end{array}$ & $\begin{array}{c}\text { No } \\
\text { fault }\end{array}$ & No fault & $\mathbf{B}_{12}$ & Lost information: $\mathrm{SLR}_{0612}, \mathrm{SLR}_{1312}, \mathrm{CB}_{0612}$ \\
\hline 9 & $\mathrm{BR}_{13}$ & - & $\mathrm{B}_{13}$ & $\begin{array}{c}\text { No } \\
\text { fault }\end{array}$ & $\begin{array}{c}\text { No } \\
\text { fault }\end{array}$ & No fault & $\mathbf{B}_{13}$ & Lost information: $\mathrm{CB}_{1206}, \mathrm{CB}_{1213}$ \\
\hline 10 & - & $\mathrm{CB}_{0613}$ & $\mathrm{~B}_{13}$ & $\begin{array}{l}\text { No } \\
\text { fault }\end{array}$ & $\begin{array}{l}\text { No } \\
\text { fault }\end{array}$ & No fault & No fault & $\begin{array}{l}\text { Lost information: } \mathrm{SLR}_{1213}, \mathrm{SLR}_{0613} \mathrm{SLR}_{1413} \\
\qquad \mathrm{CB}_{1213}, \mathrm{CB}_{1413}\end{array}$ \\
\hline
\end{tabular}

TABle 2: Diagnostic accuracy of the proposed method of IEEE 14-bus system for different $\kappa$.

\begin{tabular}{|c|c|c|c|}
\hline \multirow{2}{*}{$\kappa(\%)$} & \multicolumn{3}{|c|}{ Diagnostic accuracy } \\
\hline & Uncertainty is in the RAI & Uncertainty is in the CAAI & Uncertainty is in the RAAI \\
\hline 1 & 0.9998216 & 0.9774273 & 0.9777241 \\
\hline 3 & 0.9773322 & 0.9534217 & 0.9536811 \\
\hline 5 & 0.9402314 & 0.9212946 & 0.9217332 \\
\hline 7 & 0.9186726 & 0.8842735 & 0.8858784 \\
\hline 9 & 0.8730823 & 0.8426232 & 0.8457151 \\
\hline 10 & 0.8501379 & 0.8218934 & 0.8275321 \\
\hline 20 & 0.7038297 & 0.6807239 & 0.6884047 \\
\hline 30 & 0.6129324 & 0.5002955 & 0.5187934 \\
\hline
\end{tabular}

$$
\kappa=\frac{N_{\text {uncertain }}}{N_{\text {fault }}} \times 100 \%,
$$

where $N_{\text {fault }}$ is the number of fault alarm messages from the SCADA system and $N_{\text {uncertain }}$ is the number of the uncertain fault messages which are caused by the refuse operation, unwanted operation, and information loss of protection devices (including PRs and CBs).

In Table 2, each diagnostic accuracy for different $\kappa$ is got by computing the mean value under 1000 random tests. Note that the headers "Uncertainty is in the RAI" and "Uncertainty is in the CAAI" represent that uncertain fault alarm messages appear only in the redundant alarm information (RAI) and the core attribute alarm information (CAAI), respectively. Moreover, the "Uncertainty is in the RAAI" represents that uncertain fault alarm messages appear randomly both in RAI and CAAI, which is called random attribute alarm information (RAAI). Table 2 shows that when uncertain alarm messages contained in $\kappa$ are all RAI, the diagnostic accuracy is the highest compared to the other two situations. This is because the RAI is deleted in Step 2 (a) and is not used in the fault diagnosis process. When there is too much RAI, it will interfere with the judgment of the CAAI which should be used in the diagnosis process. Therefore, when the uncertainty is in the RAI, the diagnostic accuracy is less than $100 \%$, and it will decrease with the increasing UIRs of the RAI.

When the uncertain fault messages contained in $\kappa$ are CAAI and RAAI, the diagnostic accuracy is also high because the start information and overlimit signals of protection devices will guarantee the diagnostic accuracy. Table 2 shows that the diagnostic accuracy of our proposed method is very high when $\kappa$ is less than $5 \%$, and the diagnosis results are still acceptable when $\kappa$ is between $5 \%$ and $10 \%$.
The diagnostic accuracy drops quickly when $\kappa$ is more than $10 \%$. Fortunately, this situation will not happen unless there are attacks $[62,63]$. Therefore, we can get from Table 2 that the diagnostic accuracy of the proposed method is high for the three cases (uncertainty is in the RAI, CAAI, and RAAI, respectively) when $\kappa$ is less than $5 \%$, and the RAI has a smaller impact on fault diagnostic results.

4.1.3. Working Details of the Proposed Fault Diagnosis Method. This section takes the IEEE 14-bus system as an example to show how the proposed fault diagnosis method works.

(1) Network Partition. The system is first abstracted as a DST by the depth-first search algorithm, as shown in Figure 6(a). Then, the weight network segmentation method is employed to divide the DST, as shown in Figure 6(b). The relationship of subnetworks after division is shown in Figure 7. Note that the information on each line in Figure 7 will be used by its linked subnetworks. Finally, we get the network partition result, as shown in Figure 8.

(2) Establish srSNPS-Based Models for Subnetworks. Subnetwork S6 is considered to show how to establish an srSNPS-based fault diagnosis model for a subnetwork. The protection configuration of S6 is shown in Figure 9.

First, the ODT for S6 is established by using the protection configuration information and causality between PRs and CBs. Then, we obtain living neurons by executing Step 2 (a) in Section 3, where $\mathrm{L}_{\mathrm{C}}=\left\{\mathrm{BR}_{13}, \mathrm{BR}_{14}, \mathrm{CB}_{1213}, \mathrm{CB}_{1312}\right.$, $\left.\mathrm{CB}_{1314}, \mathrm{CB}_{1206}, \mathrm{CB}_{0613}, \mathrm{CB}_{0914}\right\}, \quad \mathrm{L}_{\mathrm{D}}=\left\{\mathrm{L}_{1213}, \mathrm{~L}_{1314}, \mathrm{~L}_{1206}\right.$, $\left.\mathrm{L}_{1306}, \mathrm{~L}_{1409}, \mathrm{~B}_{12}, \mathrm{~B}_{13}, \mathrm{~B}_{14}\right\}$. Finally, the MRDT is obtained 


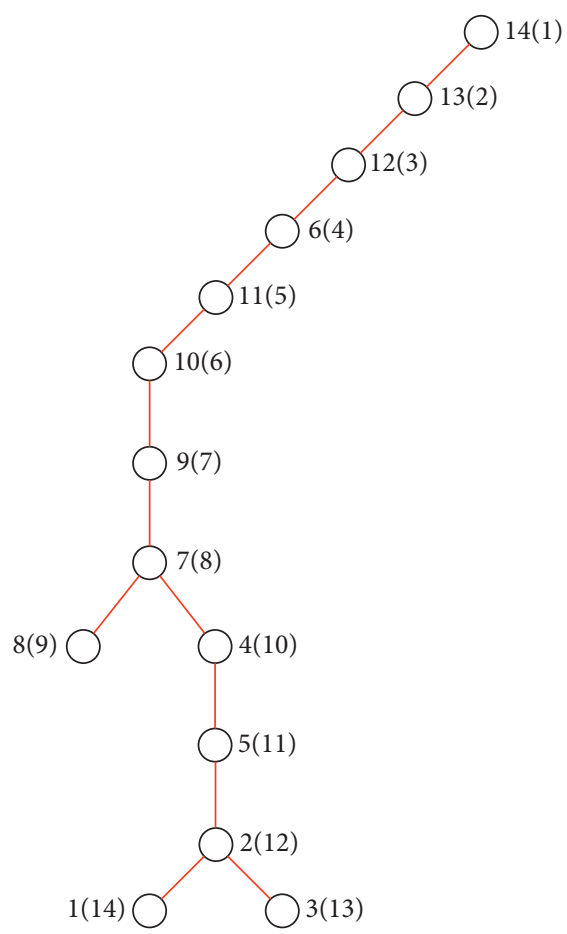

(a)

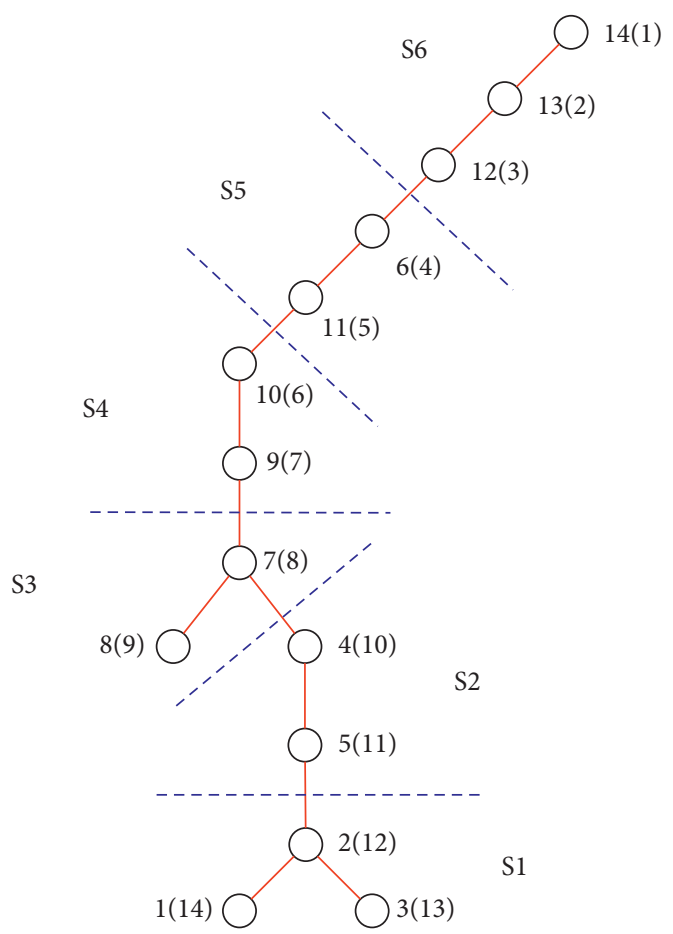

(b)

FIgure 6: (a) The DST; (b) the segmentation result.

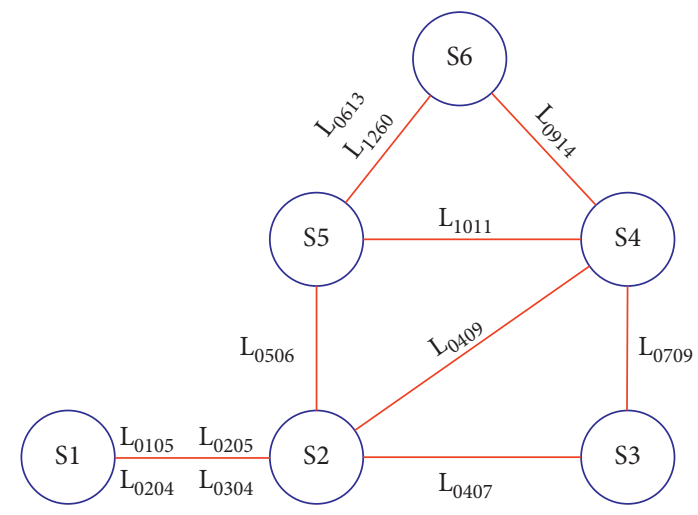

FIGURE 7: Relationship of the subnetworks.

(shown in Table 3) and accordingly the FPRS of S6 is created, as shown in Table 4.

The srSNPS-based diagnosis model for S6 is built, as shown in Figure 10, by connecting synapses based on the FPRS shown in Table 4 and the synaptic connection rule given in Definition 5.

(3) Computational Process. In this section, case 3 in Table 1 is considered as an example to show how an srSNPS-based model works.

Case 3. $\mathrm{L}_{1213}$ and $\mathrm{B}_{12}$ fault. Operated protective relays: $\mathrm{MLR}_{1213}, \mathrm{MLR}_{1213}$, and $\mathrm{SLR}_{0612}$. Tripped CBs: $\mathrm{CB}_{1206}$. Lost information: $\mathrm{CB}_{1312}$ and $\mathrm{CB}_{1213}$. The fault alarm messages obtained from the SCADA system are shown in Table 5.

According to Table 5, we can get the fault information matrices of $\mathrm{CB}_{1213}, \mathrm{CB}_{1312}$, and $\mathrm{CB}_{1206}$ which are $M_{\mathrm{CB}_{1213}}$,
$M_{\mathrm{CB}_{1312}}$, and $M_{\mathrm{CB}_{1206}}$, respectively. According to their fault information, the identification matrices $N_{\mathrm{CB}_{1213}}, N_{\mathrm{CB}_{1312}}$, and $N_{\mathrm{CB}_{1206}}$ are obtained.

$$
\begin{aligned}
M_{\mathrm{CB}_{1213}} & =\left[\begin{array}{lll}
1 & 1 & * \\
0 & 0 & * \\
0 & 0 & * \\
0 & 0 & *
\end{array}\right], \\
M_{\mathrm{CB}_{1206}} & =\left[\begin{array}{lll}
0 & 0 & 0 \\
0 & 0 & 0 \\
1 & 1 & 0 \\
0 & 0 & 0
\end{array}\right], \\
M_{\mathrm{CB}_{1312}} & =\left[\begin{array}{lll}
1 & 1 & 0 \\
0 & 0 & 0 \\
0 & 0 & 0 \\
0 & 0 & 0
\end{array}\right], \\
N_{\mathrm{CB}_{1213}} & =\left[\begin{array}{ll}
0 & 1 \\
0 & 0 \\
0 & 0 \\
0 & 0
\end{array}\right], \\
N_{\mathrm{CB}_{1312}} & =\left[\begin{array}{ll}
0 & 1 \\
0 & 0 \\
0 & 0 \\
0 & 0
\end{array}\right] . \\
N_{\mathrm{CB}_{1206}} & =\left[\begin{array}{ll}
0 & 0 \\
0 & 1 \\
0 & 0
\end{array}\right],
\end{aligned}
$$


TABLE 3: Minimum reduction decision table of S6.

\begin{tabular}{|c|c|c|c|c|c|c|c|c|}
\hline $\mathrm{BR}_{13}$ & $\mathrm{BR}_{14}$ & $\mathrm{CB}_{1213}$ & $\mathrm{CB}_{1312}$ & $\mathrm{CB}_{1314}$ & $\mathrm{CB}_{1206}$ & $\mathrm{CB}_{0613}$ & $\mathrm{CB}_{0914}$ & $\mathrm{~F}$ \\
\hline 0 & 0 & 1 & 1 & 0 & 0 & 0 & 0 & $\mathrm{~L}_{1213}$ \\
\hline 0 & 0 & 0 & 0 & 1 & 0 & 0 & 0 & $\mathrm{~L}_{1314}$ \\
\hline 0 & 0 & 0 & 0 & 0 & 1 & 0 & 0 & $\mathrm{~L}_{1206}$ \\
\hline 0 & 0 & 0 & 0 & 0 & 0 & 1 & 0 & $\mathrm{~L}_{1306}$ \\
\hline 0 & 0 & 0 & 0 & 0 & 0 & 0 & 1 & $\mathrm{~L}_{1409}$ \\
\hline 0 & 0 & 1 & 0 & 0 & 1 & 0 & 0 & $\mathrm{~B}_{12}$ \\
\hline 0 & 0 & 1 & 0 & 0 & 0 & 0 & 0 & $\mathrm{~B}_{12}$ \\
\hline 0 & 0 & 0 & 1 & 0 & 1 & 0 & 0 & $\mathrm{~B}_{12}$ \\
\hline 0 & 0 & 0 & 1 & 0 & 0 & 0 & 0 & $\mathrm{~B}_{12}$ \\
\hline 1 & 0 & 0 & 1 & 1 & 0 & 0 & 0 & $\mathrm{~B}_{13}$ \\
\hline 1 & 0 & 1 & 0 & 1 & 0 & 0 & 0 & $\mathrm{~B}_{13}$ \\
\hline 1 & 0 & 0 & 1 & 0 & 0 & 0 & 0 & $\mathrm{~B}_{13}$ \\
\hline 1 & 0 & 0 & 1 & 1 & 0 & 1 & 0 & $\mathrm{~B}_{13}$ \\
\hline 0 & 0 & 1 & 0 & 0 & 0 & 1 & 0 & $\mathrm{~B}_{13}$ \\
\hline 0 & 1 & 0 & 0 & 0 & 0 & 0 & 0 & $\mathrm{~B}_{14}$ \\
\hline 0 & 1 & 0 & 0 & 1 & 0 & 0 & 0 & $\mathrm{~B}_{14}$ \\
\hline 0 & 1 & 0 & 0 & 0 & 0 & 0 & 1 & $\mathrm{~B}_{14}$ \\
\hline 0 & 1 & 0 & 0 & 1 & 0 & 0 & 1 & $\mathrm{~B}_{14}$ \\
\hline 0 & 0 & 0 & 0 & 1 & 0 & 0 & 1 & $\mathrm{~B}_{14}$ \\
\hline
\end{tabular}

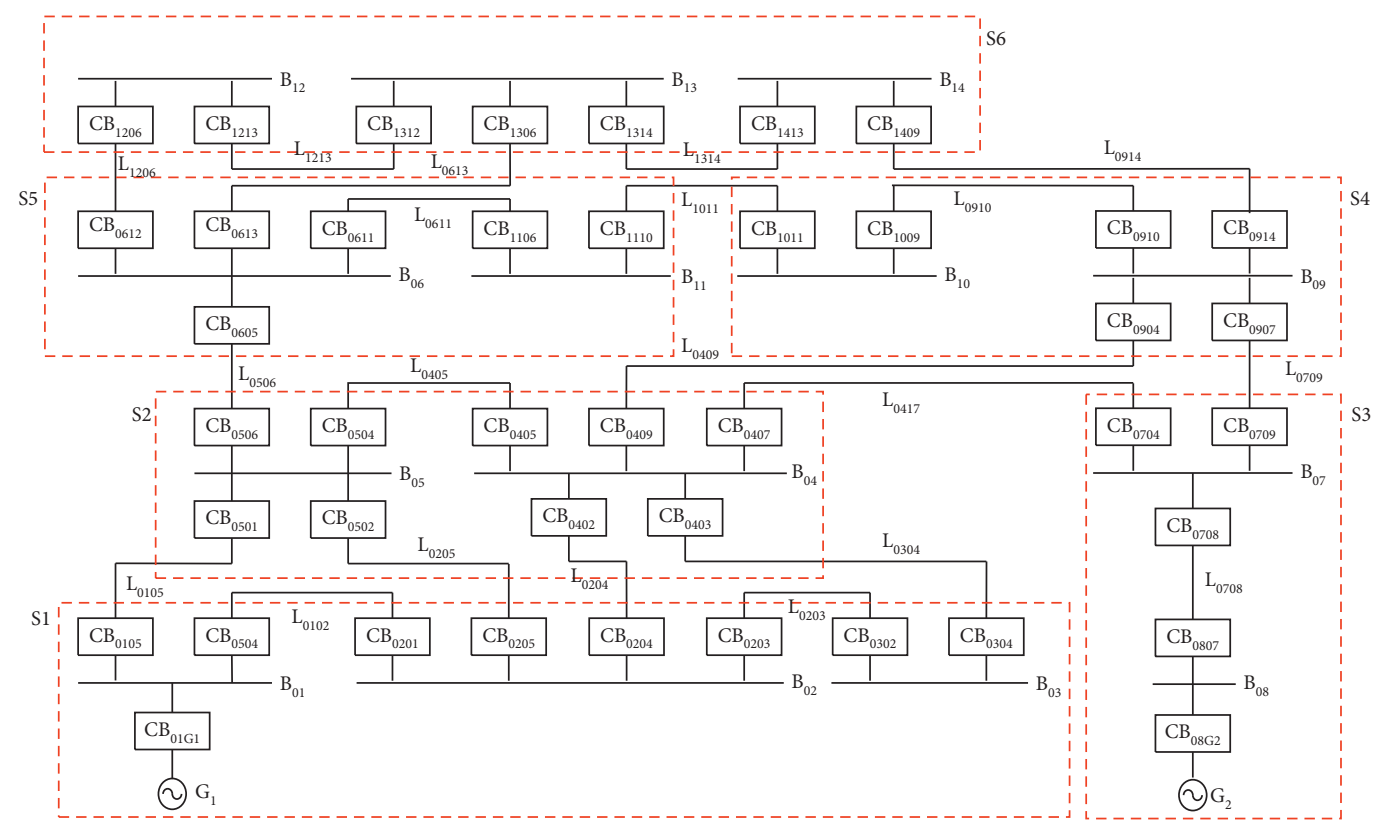

Figure 8: The partition result of the IEEE 14-bus system.

The self-updating vector of input neurons is

$$
\boldsymbol{\varepsilon}=\left[\begin{array}{cccccccc}
1 & 1 & 0 & 0 & 0 & 0 & 0 & 0 \\
\hline & \overline{0} & \overline{0} & \overline{0} & \overline{0} & \overline{1} & \overline{0} & \overline{0}
\end{array}\right]^{T} .
$$

The pulse value vector of proposition neurons before correction is

$$
\boldsymbol{\theta}=[\mathbf{O}]_{1 \times 15}^{T} .
$$

The pulse value vector of proposition neurons after correction is

$$
\boldsymbol{\theta}=\left[\begin{array}{lll}
1 & 1 & \mathbf{O}_{1 \times 13}
\end{array}\right]^{T} .
$$

When the SMRA stops, we get that

$$
\boldsymbol{\theta}=\left[\begin{array}{lllll}
\mathbf{O}_{1 \times 8} & 1 & 0 & 1 & \mathbf{O}_{1 \times 4}
\end{array}\right]^{T} .
$$

Now, both pulse values of output neurons $\sigma_{9}$ and $\sigma_{11}$ are 1. Therefore, the equipment corresponding to them is faulty, i.e., $\mathrm{L}_{1213}$ and $\mathrm{B}_{12}$ have failed.

Then, we search the PDET in Figure 5 for the fault event that " $\mathrm{B}_{12}$ is faulty," and the searching path is $P_{\text {stMLR } 1213}=$ $1 \longrightarrow P_{a c M L R 1213}=1 \longrightarrow R_{s t C B 1213}=* \longrightarrow\langle 10\rangle$, i.e., the action information of $\mathrm{CB}_{1213}$ is lost. The action information of protection devices of $\mathrm{L}_{1213}$ can be got in a similar way. Finally, we find that the action information of $\mathrm{CB}_{1206}$, $\mathrm{CB}_{1312}$, and $\mathrm{CB}_{1213}$ are lost. The computational work was performed in MATLAB running on a computer, and the 


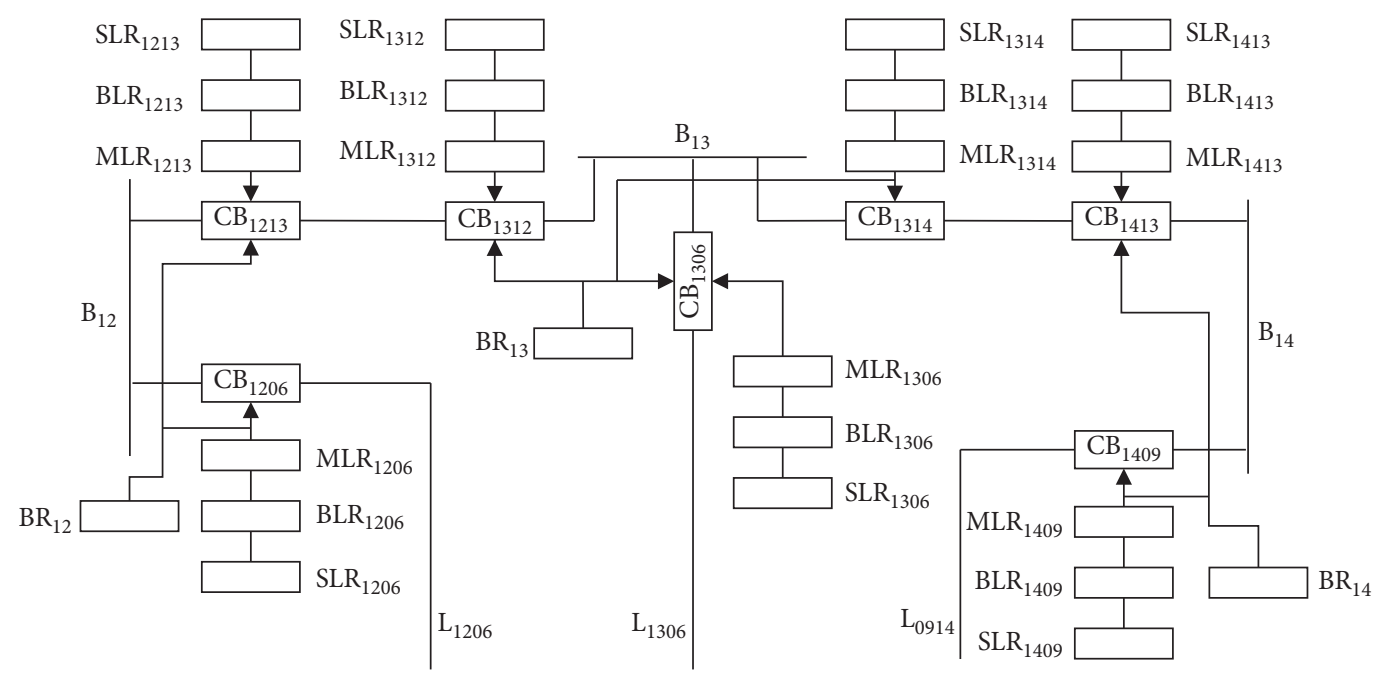

FIgURE 9: The protection configuration of S6.

TABLE 4: Fault production rule set of S6.

\begin{tabular}{|c|c|}
\hline Number & Fault production rules \\
\hline Rule 1 & 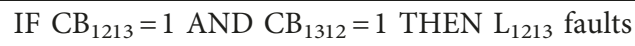 \\
\hline Rule 2 & IF $\mathrm{CB}_{1314}=1$ THEN $\mathrm{L}_{1314}$ faults \\
\hline Rule 3 & IF $\mathrm{CB}_{1206}=1$ THEN $\mathrm{L}_{1206}$ faults \\
\hline Rule 4 & IF $\mathrm{CB}_{0914}=1$ THEN $\mathrm{L}_{1409}$ faults \\
\hline Rule 5 & IF $\mathrm{CB}_{1213}=1$ OR $\mathrm{CB}_{1312}=1$ THEN $B_{12}$ faults \\
\hline Rule 6 & IF $\mathrm{CB}_{1213}=1$ AND $\mathrm{CB}_{0613}=1$ THEN $B_{13}$ faults \\
\hline Rule 7 & IF $\mathrm{BR}_{13}=1$ THEN $B_{13}$ faults \\
\hline Rule 8 & IF $\mathrm{CB}_{0914}=1 \mathrm{OR} \mathrm{BR}_{14}=1$ THEN B $\mathrm{B}_{14}$ faults \\
\hline
\end{tabular}

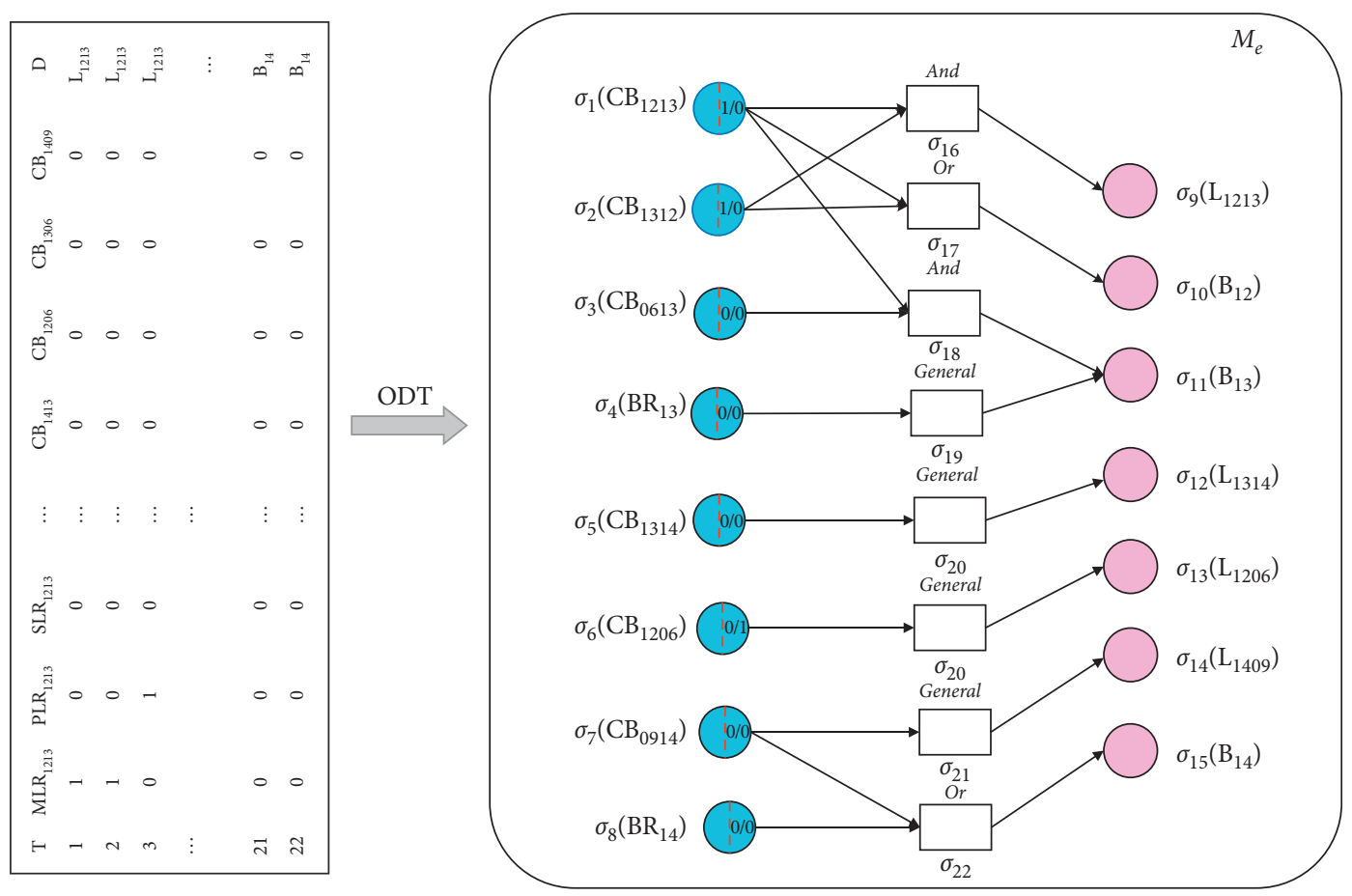

Figure 10: The srSNPS-based fault diagnosis model of S6. 
TABLE 5: Start and action information of protective devices for case 4 .

\begin{tabular}{|c|c|c|c|c|}
\hline \multicolumn{2}{|c|}{ Startup information } & \multicolumn{3}{|c|}{ Action information } \\
\hline StaI & & \multicolumn{2}{|c|}{ PRs } & CBs \\
\hline $\mathrm{MLR}_{1213}$ & 1 & $\mathrm{MLR}_{1213}$ & 1 & \multirow{4}{*}{$\mathrm{CB}_{1213}$} \\
\hline $\mathrm{BLR}_{1213}$ & 0 & $\mathrm{BLR}_{1213}$ & 0 & \\
\hline $\mathrm{SLR}_{1213}$ & 0 & $\mathrm{SLR}_{1213}$ & 0 & \\
\hline $\mathrm{BR}_{12}$ & 1 & $\mathrm{BR}_{12}$ & 1 & \\
\hline $\mathrm{MLR}_{1312}$ & 1 & $\mathrm{MLR}_{1312}$ & 1 & \multirow{4}{*}{$\mathrm{CB}_{1312}$} \\
\hline $\mathrm{BLR}_{1312}$ & 0 & $\mathrm{BLR}_{1312}$ & 0 & \\
\hline $\mathrm{SLR}_{1312}$ & 0 & $\mathrm{SLR}_{1312}$ & 0 & \\
\hline $\mathrm{BR}_{13}$ & 0 & $\mathrm{BR}_{13}$ & 0 & \\
\hline $\mathrm{MLR}_{1206}$ & 0 & $\mathrm{MLR}_{1206}$ & 0 & \multirow{2}{*}{$\mathrm{CB}_{1206}$} \\
\hline $\mathrm{BLR}_{1206}$ & 0 & $\mathrm{BLR}_{1206}$ & 0 & \\
\hline SLR $_{1206}$ & 0 & $\mathrm{SLR}_{1206}$ & 0 & \multirow{2}{*}{$\mathrm{CB}_{0612}$} \\
\hline $\mathrm{BR}_{12}$ & 1 & $\mathrm{BR}_{12}$ & 1 & \\
\hline
\end{tabular}

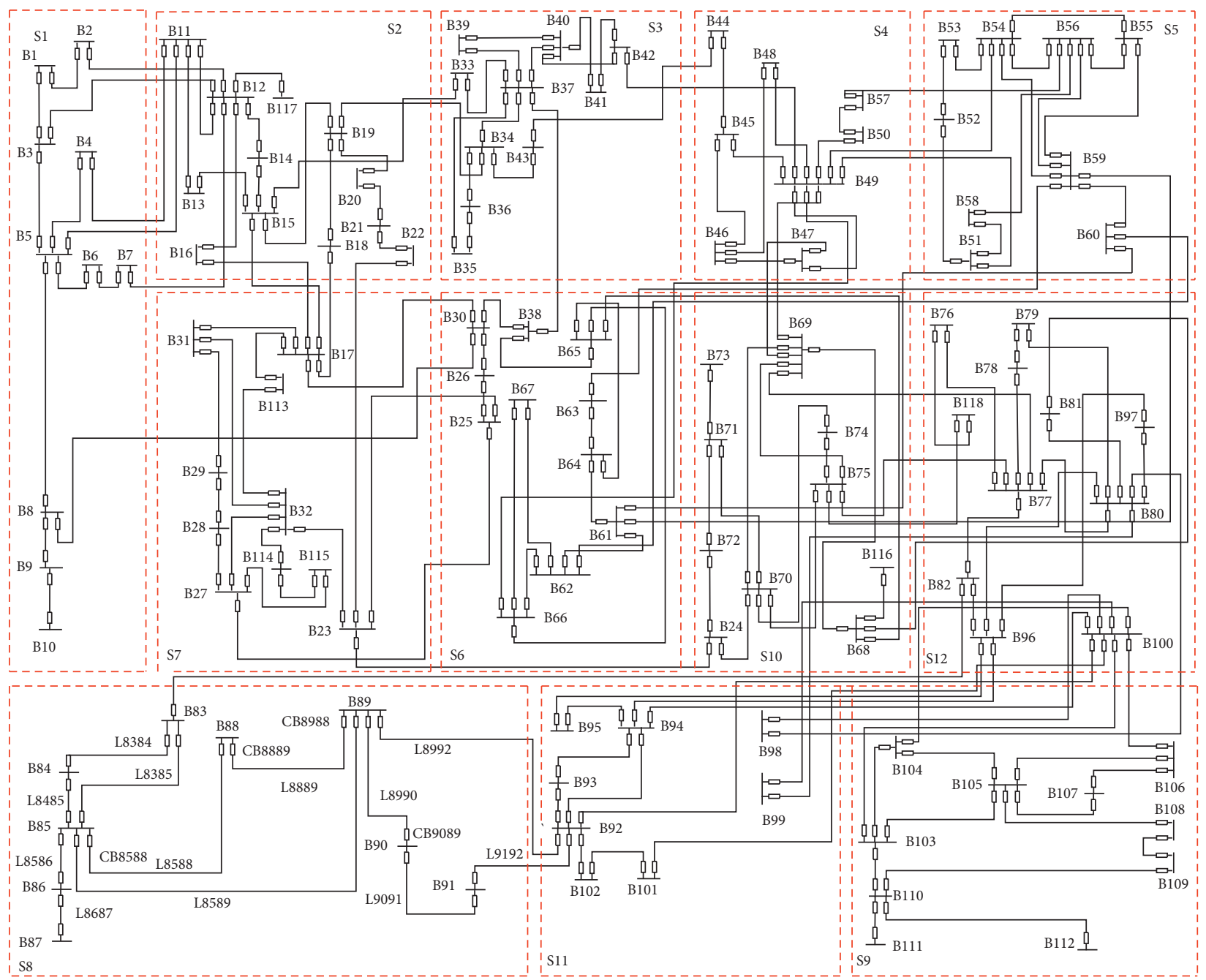

Figure 11: The partition result of the IEEE 118-bus system.

computing time is $0.001675 \mathrm{~s}$. The computer was equipped with an Intel ${ }^{\circledR}$ Core $^{\mathrm{TM}}$ i7-6700 @ 3.40 GHz CPU, 32.0 G RAM and 64 bit Windows 7 operating system.

4.2. IEEE 118-Bus System. The IEEE 118-bus system is complex, and it has 118 buses, 180 lines, 360 circuit breakers, 360 line main protective relays, 360 line first backup protective relays, 360 line second backup protective relays, and 236 bus protective relays. The system is divided into 12 subnetworks, as shown in Figure 11. For this system, ten typical cases are considered to do the comparison tests for the proposed method, CEN, FPN, and FRSNPS. The results are shown in Table 6. 
TABLE 6: Comparisons of diagnosis results between the proposed method and three typical fault diagnosis methods for the 118-bus system.

\begin{tabular}{|c|c|c|c|c|c|c|c|c|}
\hline \multirow{3}{*}{ Cases } & \multicolumn{3}{|c|}{ Preset faults } & \multirow{3}{*}{$\begin{array}{c}\text { CEN } \\
{[2]}\end{array}$} & \multirow{3}{*}{$\begin{array}{l}\text { FPN } \\
{[18]}\end{array}$} & \multirow{3}{*}{$\begin{array}{l}\text { FRSNPS } \\
{[36]}\end{array}$} & \multirow{3}{*}{$\begin{array}{l}\text { Diagnosis } \\
\text { results }\end{array}$} & \multirow{3}{*}{$\begin{array}{l}\text { The proposed method } \\
\text { Information evaluation }\end{array}$} \\
\hline & \multicolumn{2}{|c|}{$\begin{array}{l}\text { Action information of } \\
\text { protection devises }\end{array}$} & \multirow{2}{*}{$\begin{array}{c}\text { Faulty } \\
\text { equipment }\end{array}$} & & & & & \\
\hline & PRs & $\mathrm{CBs}$ & & & & & & \\
\hline 1 & $\begin{array}{c}\operatorname{MLR}_{8384} \\
\mathrm{MLR}_{8483}, \mathrm{BR}_{83}\end{array}$ & $\begin{array}{l}\mathrm{CB}_{8483} \\
\mathrm{CB}_{8385} \\
\mathrm{CB}_{8382} \\
\end{array}$ & $\begin{array}{c}\mathrm{L}_{8384} \\
\mathrm{~B}_{\mathbf{8 3}}\end{array}$ & $\begin{array}{c}\mathbf{L}_{8384} \\
\mathbf{B}_{83}\end{array}$ & $\begin{array}{c}\mathrm{L}_{8384} \\
\mathrm{~B}_{83}\end{array}$ & $\begin{array}{c}\mathrm{L}_{8384} \\
\mathrm{~B}_{83}\end{array}$ & $\begin{array}{c}\mathrm{L}_{8384} \\
\mathrm{~B}_{83}\end{array}$ & Lost information: $\mathrm{CB}_{8384}$ \\
\hline 2 & $\begin{array}{c}\mathrm{BLR}_{8384} \\
\mathrm{BLR}_{8483}, \mathrm{BR}_{83}\end{array}$ & $\begin{array}{l}\mathrm{CB}_{8483} \\
\mathrm{CB}_{8385} \\
\mathrm{CB}_{8382} \\
\end{array}$ & $\begin{array}{c}\mathrm{L}_{8384} \\
\mathrm{~B}_{\mathbf{8 3}}\end{array}$ & $\begin{array}{c}\mathrm{L}_{8384} \\
\mathrm{~B}_{\mathbf{8 3}}\end{array}$ & $\mathrm{B}_{83}$ & $\begin{array}{c}\mathrm{L}_{8384} \\
\mathrm{~B}_{83}\end{array}$ & $\begin{array}{c}\mathrm{L}_{8384} \\
\mathrm{~B}_{83}\end{array}$ & Lost information: $\mathrm{CB}_{8384}$ \\
\hline 3 & $\mathrm{BLR}_{8384}, \mathrm{BR}_{83}$ & $\begin{array}{l}\mathrm{CB}_{8384} \\
\mathrm{CB}_{8385} \\
\mathrm{CB}_{8382} \\
\end{array}$ & $\begin{array}{c}\mathrm{L}_{8384} \\
\mathrm{~B}_{83}\end{array}$ & $\mathrm{~B}_{83}$ & $\mathrm{~B}_{83}$ & $\mathrm{~B}_{83}$ & $\begin{array}{c}\mathrm{L}_{8384} \\
\mathrm{~B}_{83}\end{array}$ & Lost information: $\mathrm{BLR}_{8483} \mathrm{CB}_{8483}$ \\
\hline 4 & $\mathrm{BR}_{88}, \mathrm{BR}_{89}$ & $\begin{array}{l}\mathrm{CB}_{8885} \\
\mathrm{CB}_{8889} \\
\mathrm{CB}_{8988} \\
\mathrm{CB}_{8985} \\
\end{array}$ & $\begin{array}{l}\mathbf{B}_{88} \\
\mathbf{B}_{89}\end{array}$ & $\begin{array}{l}\mathbf{B}_{88} \\
\mathbf{B}_{89}\end{array}$ & $\begin{array}{l}B_{88} \\
B_{89}\end{array}$ & $\begin{array}{l}\mathbf{B}_{88} \\
\mathbf{B}_{89}\end{array}$ & $\begin{array}{l}\mathbf{B}_{88} \\
\mathbf{B}_{89}\end{array}$ & Lost information: $\mathrm{CB}_{8990}, \mathrm{CB}_{8992}$ \\
\hline 5 & $\mathrm{BR}_{85}$ & $\begin{array}{l}\mathrm{CB}_{8583} \\
\mathrm{CB}_{8589} \\
\mathrm{CB}_{8885} \\
\mathrm{CB}_{8889} \\
\end{array}$ & $\begin{array}{l}\mathbf{B}_{85} \\
\mathbf{B}_{88}\end{array}$ & $\mathrm{~B}_{88}$ & $\mathrm{~B}_{88}$ & $\begin{array}{l}\mathbf{B}_{85} \\
\mathbf{B}_{88}\end{array}$ & $\begin{array}{l}\mathbf{B}_{85} \\
\mathbf{B}_{88}\end{array}$ & $\begin{array}{l}\text { Lost information: } \mathrm{BR}_{88}, \mathrm{CB}_{8584}, \mathrm{CB}_{8588} \text {, } \\
\qquad \mathrm{CB}_{8564}\end{array}$ \\
\hline 6 & $\begin{array}{l}\mathrm{BR}_{88}, \mathrm{BR}_{89} \\
\mathrm{BLR}_{8990} \\
\mathrm{SLR}_{9089}\end{array}$ & $\begin{array}{l}\mathrm{CB}_{8885} \\
\mathrm{CB}_{8992} \\
\mathrm{CB}_{9091} \\
\end{array}$ & $\begin{array}{c}\mathbf{B}_{88} \\
\mathbf{B}_{89} \\
\mathbf{L}_{8990}\end{array}$ & $\mathrm{~B}_{88}$ & $\begin{array}{c}\mathrm{B}_{88} \\
\mathrm{~L}_{8990}\end{array}$ & $\begin{array}{c}\mathrm{B}_{88} \\
\mathrm{~L}_{8990}\end{array}$ & $\begin{array}{c}\mathbf{B}_{88} \\
\mathbf{B}_{89} \\
\mathrm{~L}_{8990}\end{array}$ & $\begin{array}{l}\text { Lost information: } \mathrm{CB}_{8889}, \mathrm{CB}_{8988} \text {, } \\
\qquad \mathrm{CB}_{8985}, \mathrm{CB}_{8990}\end{array}$ \\
\hline 7 & - & $\begin{array}{c}\mathrm{CB}_{8885} \\
\mathrm{CB}_{8889} \mathrm{CB}_{8992} \\
\mathrm{CB}_{9091} \\
\end{array}$ & $\begin{array}{l}\mathbf{B}_{88} \\
\mathbf{B}_{89} \\
\mathbf{B}_{90}\end{array}$ & $\begin{array}{l}\text { No } \\
\text { fault }\end{array}$ & $\mathrm{B}_{88}$ & $\mathrm{~B}_{88}$ & $\begin{array}{l}B_{88} \\
B_{89} \\
B_{90} \\
\end{array}$ & $\begin{array}{l}\text { Lost information: } \mathrm{BR}_{88}, \mathrm{BR}_{89}, \mathrm{BR}_{90} \text {, } \\
\qquad \mathrm{CB}_{8988}, \mathrm{CB}_{8985}, \mathrm{CB}_{8990}, \mathrm{CB}_{9089}\end{array}$ \\
\hline 8 & $\mathrm{BR}_{89}, \mathrm{SLR}_{8589}$ & $\begin{array}{l}\mathrm{CB}_{8885} \\
\mathrm{CB}_{8992} \\
\mathrm{CB}_{8990} \\
\mathrm{CB}_{8589} \\
\mathrm{CB}_{8586} \\
\mathrm{CB}_{9089} \\
\end{array}$ & $\begin{array}{r}\mathbf{B}_{88} \\
\mathbf{B}_{89} \\
\mathbf{B}_{90} \\
\mathrm{~L}_{8589}\end{array}$ & $\begin{array}{l}\text { No } \\
\text { fault }\end{array}$ & $\begin{array}{l}\text { No } \\
\text { fault }\end{array}$ & $\mathrm{B}_{89}$ & $\begin{array}{l}\mathbf{B}_{88} \\
\mathbf{B}_{89} \\
\mathrm{~B}_{90} \\
\mathrm{~L}_{8589}\end{array}$ & $\begin{array}{l}\text { Lost information: } \mathrm{BR}_{88}, \mathrm{BR}_{89}, \mathrm{MLR}_{8985} \text {, } \\
\mathrm{CB}_{8889}, \mathrm{CB}_{8985}, \mathrm{CB}_{8988}, \mathrm{CB}_{8584}, \mathrm{CB}_{8583}, \\
\mathrm{CB}_{8588}, \mathrm{CB}_{9091}\end{array}$ \\
\hline 9 & - & $\begin{array}{l}\mathrm{CB}_{8885} \\
\mathrm{CB}_{8992} \\
\mathrm{CB}_{8990} \\
\mathrm{CB}_{8589} \\
\mathrm{CB}_{8586} \\
\mathrm{CB}_{9089} \\
\end{array}$ & $\begin{array}{r}\mathbf{B}_{88} \\
\mathbf{B}_{89} \\
\mathrm{~B}_{90} \\
\mathrm{~L}_{8589}\end{array}$ & $\begin{array}{l}\text { No } \\
\text { fault }\end{array}$ & $\begin{array}{l}\text { No } \\
\text { fault }\end{array}$ & No fault & $\begin{array}{c}\mathbf{B}_{88} \\
\mathbf{B}_{89} \\
\mathbf{B}_{90} \\
\mathrm{~L}_{8589}\end{array}$ & $\begin{array}{l}\text { Lost information: } \mathrm{BR}_{88}, \mathrm{BR}_{89}, \mathrm{BR}_{90} \\
\mathrm{MLR}_{8985}, \mathrm{CB}_{8889}, \mathrm{CB}_{8985}, \mathrm{CB}_{8988} \\
\mathrm{CB}_{8584}, \mathrm{CB}_{8583}, \mathrm{CB}_{8588}, \mathrm{CB}_{9091}\end{array}$ \\
\hline 10 & $\begin{array}{l}\mathrm{BR}_{85}, \mathrm{BR}_{89} \\
\mathrm{BLR}_{8985}\end{array}$ & $\begin{array}{l}\mathrm{CB}_{8583} \\
\mathrm{CB}_{8588} \\
\mathrm{CB}_{8584} \\
\mathrm{CB}_{8589} \\
\mathrm{CB}_{8586} \\
\mathrm{CB}_{8992} \\
\mathrm{CB}_{8985} \\
\mathrm{CB}_{8990}\end{array}$ & $\begin{array}{l}\mathbf{B}_{85} \\
\mathbf{B}_{89} \\
\mathbf{B}_{90}\end{array}$ & $\begin{array}{l}\mathrm{B}_{85} \\
\mathrm{~B}_{89} \\
\mathrm{~B}_{90} \\
\mathrm{~L}_{8589}\end{array}$ & $\begin{array}{l}\mathrm{B}_{85} \\
\mathrm{~B}_{89} \\
\mathrm{~B}_{90} \\
\mathrm{~L}_{8589}\end{array}$ & $\begin{array}{l}\mathrm{B}_{85} \\
\mathrm{~B}_{89} \\
\mathrm{~B}_{90} \\
\mathrm{~L}_{8589}\end{array}$ & $\begin{array}{l}\mathbf{B}_{85} \\
\mathbf{B}_{89} \\
\mathbf{B}_{90}\end{array}$ & $\begin{array}{c}\text { Lost information: } \mathrm{BR}_{90}, \mathrm{CB}_{8988}, \mathrm{CB}_{8984} \text {, } \\
\mathrm{CB}_{9091}, \mathrm{CB}_{8588} \text { False information: } \\
\mathrm{BLR}_{8589}\end{array}$ \\
\hline
\end{tabular}

In Table 6, cases 1-4 have faults with less information loss, while cases 5-10 have faults with serious information loss or many information errors. For cases 1 and 2, all the four methods can diagnose the right faulty equipment. For case 3 , the FPN is failed, while the other three methods are successful. For case 4, only our method can diagnose the right faults and all the three other methods have missed diagnosis of faulty equipment. For case 5, CEN and FPN are failed, while the FRSNPS and the proposed method are successful. For case 6, theCEN, FPN, and FRSNPS have missed diagnosis, while the proposed method can diagnose all the right faults. When the lost information increases, such as cases 7-9, the missed diagnosis of faulty equipment for the CEN, FPN, and FRSNPS becomes more serious, while the proposed method is still successful. Furthermore, for case 10, not only many fault alarm messages are lost but also the false information is involved. The results show that, for this case, our method is still valid, while all the other three methods misdiagnose the faults.

This is because that the redundant fault alarm information reduction ability of the apoptosis algorithm (Algorithm 1) and the false information correction ability of self-updating rules guarantee the high fault tolerance of the proposed 
TABLE 7: Diagnostic accuracy of the proposed method of the IEEE 118-bus system for different $\kappa$.

\begin{tabular}{|c|c|c|c|}
\hline \multirow{2}{*}{$\kappa(\%)$} & \multicolumn{3}{|c|}{ Diagnostic accuracy } \\
\hline & Uncertainty is in the RAI & Uncertainty is in the CAAI & Uncertainty is in the RAAI \\
\hline 1 & 0.9890323 & 0.9653048 & 0.9654454 \\
\hline 3 & 0.9680938 & 0.9479018 & 0.9482381 \\
\hline 5 & 0.9490233 & 0.9131209 & 0.9137391 \\
\hline 7 & 0.9031862 & 0.8750283 & 0.8785287 \\
\hline 9 & 0.8659286 & 0.8348030 & 0.8374533 \\
\hline 10 & 0.8498392 & 0.8208349 & 0.8267387 \\
\hline 20 & 0.6921393 & 0.6534890 & 0.6622308 \\
\hline 30 & 0.5812309 & 0.4921039 & 0.5130250 \\
\hline
\end{tabular}

method. Therefore, we can see from Table 6 that the proposed method can also obtain satisfying results for a complex system with fault information loss and information errors.

Besides, to further demonstrate the effectiveness and superiority of our proposed method, the IEEE 118-bus system is employed to do disturbed tests for different $\kappa$. The disturbed test method is the same as that of the IEEE 14-bus system, and test results are shown in Table 7 . Table 7 shows that when uncertain alarm messages appear only in the RAI, the diagnostic accuracy is the highest. Besides, when the uncertain fault messages are contained in the CAAI and RAAI, the diagnostic accuracy is also high. Comparing the data in Tables 2 and 7, we find that, for the same case, the diagnostic accuracy of the IEEE 118-bus system is only 0.01 lower than that of the IEEE 14-bus system on average. Therefore, Table 7 shows that the proposed method is still feasible and effective with high diagnostic accuracy and fault tolerance for different kinds of faults for complex systems.

\section{Conclusions}

To reduce the error caused by historical statistic, expertise, and redundant fault information, this paper proposes a fault diagnosis method of power transmission lines based on an srSNPS, considering the biological apoptosis mechanism. The attribute reduction capacity of rough sets and the apoptosis mechanism of neurons are integrated in a system in the framework of membrane computing for the first time. The srSNPS can deal with uncertain and incomplete fault alarm messages without historical statistic and expert experience, while its apoptosis algorithm for CNs can delete the redundant fault information before modeling. This simplifies the problem complexity. Besides, the transmission network partition improves the topological adaptive ability. Case studies show that the proposed method has high diagnostic accuracy and fault tolerance with good diagnosis result interpretability and fast speed. Owing to the complexity of fault diagnosis for power systems, future work will focus on different applications, such as power plants, substations, distribution networks, integrated energy system, and cyber-physical power system considering network attacks.

\section{Nomenclature}

SCADA: Supervisory control and data acquisition

$\begin{array}{ll}\text { ES: } & \text { Expert system } \\ \text { ANN: } & \text { Artificial neural network } \\ \text { BN: } & \text { Bayesian network } \\ \text { PN: } & \text { Petri net } \\ \text { CEN: } & \text { Cause-effect network } \\ \text { OM: } & \text { Optimization method } \\ \text { FL: } & \text { Fuzzy logic } \\ \text { RS: } & \text { Rough set } \\ \text { SNPS: } & \text { Spiking neural P system } \\ \text { FRRN: } & \text { Fuzzy reasoning with real numbers } \\ \text { FRFN: } & \text { Fuzzy reasoning with fuzzy numbers } \\ \text { srSNPS: } & \text { Spiking neural P system with self-updating rules } \\ \text { SMRA: } & \text { Self-updating matrix reasoning algorithm } \\ \text { DSA: } & \text { Depth-first search algorithm } \\ \text { WNSM: } & \text { Weight network segmentation method } \\ \text { PDET: } & \text { Protection device event tree } \\ \text { DN: } & \text { Decision-making neuron } \\ \text { CN: } & \text { Condition neuron } \\ \text { PR: } & \text { Protective relay } \\ \text { CB: } & \text { Circuit breaker } \\ \text { PN: } & \text { Proposition neuron } \\ \text { RN: } & \text { Rule neuron } \\ \text { CIE: } & \text { Conditional information entropy } \\ \text { MRDT: } & \text { Minimum reduction decision table } \\ \text { FPRS: } & \text { Fault production rule set } \\ \text { ODT: } & \text { Original decision table } \\ \text { FPN: } & \text { Fuzzy Petri net } \\ \text { FRSNPS: } & \text { Fuzzy reasoning spiking neural P system } \\ \text { UIA: } & \text { Uncertain information ratio } \\ \text { RAI: } & \text { Redundant alarm information } \\ \text { CAAI: } & \text { Core attribute alarm information } \\ \text { RAAI: } & \text { Random attribute alarm information. } \\ & \end{array}$

\section{Data Availability}

The data used to support the findings of this study are available from the corresponding author upon request.

\section{Conflicts of Interest}

All authors declare that they have no conflicts of interest.

\section{Acknowledgments}

This research was partially funded by grants from the National Natural Science Foundation of China (61703345), the 
Key Fund Project of the Sichuan Provincial Education Department (18ZA0459), the Chunhui Project Foundation of the Education Department of China (Z201980), the Key Scientific Research Fund Project of Xihua University (Z17108), supported by the Open Research Subject of Key Laboratory of Fluid and Power Machinery (Xihua University), Ministry of Education (szjj2019-27), the Young Scholars Reserve Talents Support Project of Xihua University, and the Innovation Fund for Graduate Students of Xihua University (ycjj2019047).

\section{References}

[1] Y. Zhu, L. Huo, and J. Lu, "Bayesian networks-based approach for power systems fault diagnosis," IEEE Transactions on Power Delivery, vol. 21, no. 2, pp. 473-477, 2018.

[2] W.-H. Chen, "Online fault diagnosis for power transmission networks using fuzzy digraph models," IEEE Transactions on Power Delivery, vol. 27, no. 2, pp. 688-698, 2012.

[3] S. Roostaee, M. S. Thomas, and S. Mehfuz, "Experimental studies on impedance based fault location for long transmission lines," Protection and Control of Modern Power Systems, vol. 2, no. 1, pp. 169-177, 2017.

[4] T. Wang, G. Zhang, J. Zhao, Z. He, J. Wang, and M. J. PerezJimenez, "Fault diagnosis of electric power systems based on fuzzy reasoning spiking neural P systems," IEEE Transactions on Power Systems, vol. 30, no. 3, pp. 1182-1194, 2015.

[5] S. Wang and D. Zhao, "Research review and prospects for power grid fault diagnosis," Automation of Electric Power System, vol. 41, no. 19, pp. 164-175, 2017.

[6] S. Lin, Z. He, and D. Zhao, "Review and development on fault diagnosis for power grid," Power System Protection and Control, vol. 38, no. 4, pp. 140-150, 2010.

[7] Y. Cui, J. Shi, and Z. Wang, "Power system fault reasoning and diagnosis based on the improved temporal constraint network," IEEE Transactions on Power Delivery, vol. 31, no. 3, pp. 946-954, 2016.

[8] Z. A. Vale and A. Machado e Moura, "An expert system with temporal reasoning for alarm processing in power system control centers," IEEE Transactions on Power Systems, vol. 8, no. 3, pp. 1307-1314, 1993.

[9] D. Ma, Y. Liang, X. Zhao, R. Guan, and X. Shi, "Multi-BP expert system for fault diagnosis of powersystem," Engineering Applications of Artificial Intelligence, vol. 26, no. 3, pp. 937-944, 2013.

[10] H.-J. Lee, D.-Y. Park, B.-S. Ahn, Y.-M. Park, J.-K. Park, and S. S. Venkata, "A fuzzy expert system for the integrated fault diagnosis," IEEE Transactions on Power Delivery, vol. 15, no. 2, pp. $833-838,2000$.

[11] D. Thukaram, H. P. Khincha, and H. P. Vijaynarasimha, "Artificial neural network and support vector machine approach for locating faults in radial distribution systems," IEEE Transactions on Power Delivery, vol. 20, no. 2, pp. 710-721, 2005.

[12] G. Rigatos, A. Piccolo, and P. Siano, "Neural network-based approach for early detection of cascading events in electric power systems," IET Generation, Transmission \& Distribution, vol. 3, no. 7, pp. 650-665, 2009.

[13] V. Miranda, A. R. G. Castro, and S. Lima, "Diagnosing faults in power transformers with autoassociative neural networks and mean shift," IEEE Transactions on Power Delivery, vol. 27, no. 3, pp. 1350-1357, 2012.
[14] A. Flores Novelo, E. Quiles Cucarella, E. Garcia Moreno, and F. Morant Anglada, "Fault diagnosis of electric transmission lines using modular neural networks," IEEE Latin America Transactions, vol. 14, no. 8, pp. 3663-3668, 2016.

[15] Z. Yongli, H. Limin, and L. Jinling, "Bayesian networks-based approach for power systems fault diagnosis," IEEE Transactions on Power Delivery, vol. 21, no. 2, pp. 634-639, 2006.

[16] M. M. Mansour, M. A. A. Wahab, and W. M. Soliman, "Bayesian networks for fault diagnosis of a large power station and its transmission lines," Electric Power Components and Systems, vol. 40, no. 8, pp. 845-863, 2012.

[17] B. Cai, L. Huang, and M. Xie, "Bayesian networks in fault diagnosis," IEEE Transactions on Industrial Informatics, vol. 13, no. 5, pp. 2227-2240, 2017.

[18] B. Cai, Y. Liu, Q. Fan et al., "Multi-source information fusion based fault diagnosis of ground-source heat pump using Bayesian network," Applied Energy, vol. 114, pp. 1-9, 2014.

[19] J. Sun, S.-Y. Qin, and Y. H. Song, "Fault diagnosis of electric power systems based on fuzzy Petri nets," IEEE Transactions on Power Systems, vol. 19, no. 4, pp. 2053-2059, 2004.

[20] X. Luo and M. Kezunovic, "Implementing fuzzy reasoning Petri-net for fault section estimation," IEEE Transactions on Power Delivery, vol. 23, no. 2, pp. 676-685, 2008.

[21] Y. Zhang, Y. Zhang, F. Wen et al., "A fuzzy Petri net based approach for fault diagnosis in power systems considering temporal constraints," International Journal of Electrical Power \& Energy Systems \& Energy Systems, vol. 78, pp. 215224, 2016.

[22] X. Tong, H. Xie, and M. Sun, "Power system fault diagnosis model based on layered Petri net considering temporal constraint checking," Automation of Electric Power System, vol. 37, no. 6, pp. 63-64, 2013.

[23] X. Zhang, S. Yue, and X. Zha, "Method of power grid fault diagnosis using intuitionistic fuzzy Petri nets," IET Generation, Transmission \& Distribution, vol. 12, no. 2, pp. 295-302, 2018.

[24] Z. Jiang, Z. Li, N. Wu, and M. Zhou, "A Petri net approach to fault diagnosis and restoration for power transmission systems to avoid the output interruption of substations," IEEE Systems Journal, vol. 12, no. 3, pp. 2566-2576, 2018.

[25] W.-H. Chen, S.-H. Tsai, and H.-I. Lin, "Fault section estimation for power networks using logic cause-effect models," IEEE Transactions on Power Delivery, vol. 26, no. 2, pp. 963-971, 2011.

[26] F. Wen and Z. Han, "Fault section estimation in power systems using a genetic algorithm," Electric Power Systems Research, vol. 34, no. 3, pp. 165-172, 1995.

[27] W. Guo, F. Wen, Z. Liao, L. Wei, and J. Xin, "An analytic model-based approach for power system alarm processing employing temporal constraint network," IEEE Transactions on Power Delivery, vol. 25, no. 4, pp. 2435-2447, 2010.

[28] X. Lin, S. Ke, Z. Li, H. Weng, and X. Han, "A fault diagnosis method of power systems based on improved objective function and genetic algorithm-tabu search," IEEE Transactions on Power Delivery, vol. 25, no. 3, pp. 1268-1274, 2010.

[29] Y. Zhang, C. Y. Chung, F. Wen, and J. Zhong, "An analytic model for fault diagnosis in power systems utilizing redundancy and temporal information of alarm messages," IEEE Transactions on Power Systems, vol. 31, no. 6, pp. 4877-4886, 2016.

[30] T. Wang, S. Zeng, G. Zhang, M. J. Pérez-Jiménez, and J. Wang, "Fault section estimation of power systems with optimization spiking neural P systems," Romanian Journal of Information Science and Technology, vol. 18, no. 3, pp. 240-255, 2015. 
[31] J.-T. Peng, C. F. Chien, and T. L. B. Tseng, "Rough set theory for data mining for fault diagnosis on distribution feeder," IEE Proceedings-Generation, Transmission and Distribution, vol. 151, no. 6, pp. 689-697, 2004.

[32] Y. Zhang, Z. He, J. Zhao et al., "A power network fault diagnosis method based on rough set theory and naive Bayesian networks," Power System Technology, vol. 31, no. 1, pp. 37-43, 2007.

[33] C.-L. Hor, P. A. Crossley, and S. J. Watson, "Building knowledge for substation-based decision support using rough sets," IEEE Transactions on Power Delivery, vol. 22, no. 3, pp. 1372-1379, 2007.

[34] Q. Sun, C. Wang, Z. Wang, and X. Liu, "A fault diagnosis method of smart grid based on rough sets combined with genetic algorithm and tabu search," Neural Computing and Applications, vol. 23, no. 7-8, pp. 2023-2029, 2013.

[35] R. Ghimire, C. Zhang, and K. R. Pattipati, "A rough settheory-based fault-diagnosis method for an electric powersteering system," IEEE/ASME Transactions on Mechatronics, vol. 23, no. 5, pp. 2042-2053, 2018.

[36] H. Peng, J. Wang, M. J. Pérez-Jiménez, H. Wang, J. Shao, and T. Wang, "Fuzzy reasoning spiking neural P system for fault diagnosis," Information Sciences, vol. 235, pp. 106-116, 2013.

[37] G. Xiong, D. Shi, L. Zhu, and X. Duan, "A new approach to fault diagnosis of power systems using fuzzy reasoning spiking neural P systems," Mathematical Problems in Engineering, vol. 2013, no. 1, Article ID 815352, 13 pages, 2013.

[38] M. Tu, J. Wang, H. Peng et al., "Application of adaptive fuzzy spiking neural P systems in fault diagnosis of power systems," Chinese Journal of Electronics, vol. 23, no. 1, pp. 87-92, 2014.

[39] L. Pan, G. Păun, G. Zhang, and F. Neri, "Spiking neural P systems with communication on request," International Journal of Neural Systems, vol. 27, no. 8, p. 1750042, 2017.

[40] T. Wu, A. Păun, Z. Zhang et al., "Spiking neural P systems with communication on request," IEEE Transactions on Neural Networks and Learning Systems, vol. 29, no. 8, pp. 3349-3360, 2018.

[41] G. Păun, G. Rozenberg, and A. Salomaa, The Oxford Handbook of Membrane Computing, Oxford University Press, London, UK, 2009.

[42] T. Wang, J. Wang, J. Ming et al., “Application of neural-like P systems with state values for power coordination of photovoltaic/battery microgrids," IEEE Access, vol. 6, pp. 4663046642, 2018.

[43] M. Ionescu, G. Păun, and T. Yokomori, "Spiking neural P systems," Fundamenta Informaticae, vol. 71, no. 2-3, pp. 279-308, 2006.

[44] T. Wang, X. Wei, T. Huang et al., "Modeling fault propagation paths in power systems: a new framework based on event SNP systems with neurotransmitter concentration," IEEE Access, vol. 7, pp. 12798-12808, 2019.

[45] J. Wang, J. M. Pérez-Jiménez, H. Peng, P. Shi, and M. Tu, “A fault diagnosis method of power systems based on an improved adaptive fuzzy spiking neural $\mathrm{P}$ systems and PSO algorithms," Chinese Journal of Electronics, vol. 25, no. 2, pp. 320-327, 2016.

[46] T. Wang, G. Zhang, M. J. Pérez-Jiménez, and J. Cheng, "Weighted fuzzy reasoning spiking neural P systems: application to fault diagnosis in traction power supply systems of high-speed railways," Journal of Computational and Theoretical Nanoscience, vol. 12, no. 7, pp. 1103-1114, 2015.

[47] Y. He, T. Wang, K. Huang et al., "Fault diagnosis of metro traction power systems using a modified fuzzy reasoning spiking neural P system," Romanian Journal of Information Science and Technology, vol. 18, no. 3, pp. 256-272, 2015.
[48] K. Huang, T. Wang, Y. He, G. Zhang, and M. J. Pérez-Jiménez, "Temporal fuzzy reasoning spiking neural $\mathrm{P}$ systems with real numbers for power system fault diagnosis," Journal of Computational and Theoretical Nanoscience, vol. 13, no. 6, pp. 3804-3814, 2016.

[49] T. Wang, G. Zhang, and M. J. Pérez-Jiménez, "Fuzzy membrane computing: theory and applications," International Journal of Computers Communications \& Control, vol. 10, no. 6, pp. 144-175, 2015.

[50] C. Tao, W. Yu, J. Wang, H. Peng, K. Chen, and J. Ming, "Fault diagnosis of power systems based on triangular fuzzy spiking neural P systems," Bio-Inspired Computing-Theories and Applications, vol. 618, pp. 385-398, 2017.

[51] W. Yu, J. Wang, H. Peng et al., "Fault diagnosis of power systems using fuzzy reasoning spiking neural $\mathrm{P}$ systems with interval-valued fuzzy numbers," Romanian Journal of Information Science and Technology, vol. 1, no. 20, pp. 5-17, 2017.

[52] H. Peng, J. Wang, J. Ming et al., "Fault diagnosis of power systems using intuitionistic fuzzy spiking neural P systems," IEEE Transactions on Smart Grid, vol. 9, no. 5, pp. 4777-4784, 2018.

[53] T. Wang, X. Wei, T. Huang et al., "Cascading failures analysis considering extreme virus propagation of cyber-physical systems in smart grids," Complexity, vol. 2019, Article ID 7428458, 15 pages, 2019.

[54] X. Wei, S. Gao, T. Huang, T. Wang, and W. Fan, "Identification of two vulnerability features: a new framework for electrical networks based on the load redistribution mechanism of complex networks," Complexity, vol. 2019, Article ID 3531209, 14 pages, 2019.

[55] X. Wei, S. Gao, T. Huang, E. Bompard, R. Pi, and T. Wang, "Complex network-based cascading faults graph for the analysis of transmission network vulnerability," IEEE Transactions on Industrial Informatics, vol. 15, no. 3, pp. 1265-1276, 2019.

[56] H. Rong, K. Yi, G. Zhang, J. Dong, P. Paul, and Z. Huang, "Automatic implementation of fuzzy reasoning spiking neural P systems for diagnosing faults in complex power systems," Complexity, vol. 2019, Article ID 2635714, 16 pages, 2019.

[57] Z. Pawlak, "Rough sets and intelligent data analysis," Information Sciences, vol. 147, no. 1-4, pp. 1-12, 2002.

[58] R. Jensen and Q. Shen, Computational Intelligence and Feature Selection: Rough and Fuzzy Approaches, Wiley-IEEE Press, Hoboken, NJ, USA, 2008.

[59] H. Li, X. Zhou, and H. Bing, "Method to determine $\alpha$ in rough set model based on connection degree," Journal of Systems Engineering and Electronics, vol. 20, no. 1, pp. 98-105, 2009.

[60] T. Bi, L. Jiao, Z. Yan et al., "Graph partitioning method for distributed fault section estimation system in power networks," Automation of Electric Power System, vol. 25, no. 16, pp. 16-21, 2001.

[61] T. Bi, Y. Ni, C. M. Shen, and F. F. Wu, "Efficient multiway graph partitioning method for fault section estimation in large-scale power networks," IEE Proceedings-Generation, Transmission and Distribution, vol. 149, no. 3, pp. 289-294, 2002.

[62] W. Fan and Y. Liao, "Wide area measurements based fault detection and location method for transmission lines," Protection and Control of Modern Power Systems, vol. 4, no. 4, pp. 53-64, 2002.

[63] A. Mohammadi, C. Yang, and Q. Chen, "Attack detection/ Isolation via a secure multisensor fusion framework for cyberphysical systems," Complexity, vol. 2018, Article ID 1240149, 8 pages, 2018. 


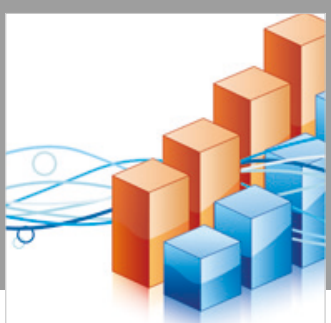

Advances in

Operations Research

\section{-n-m}
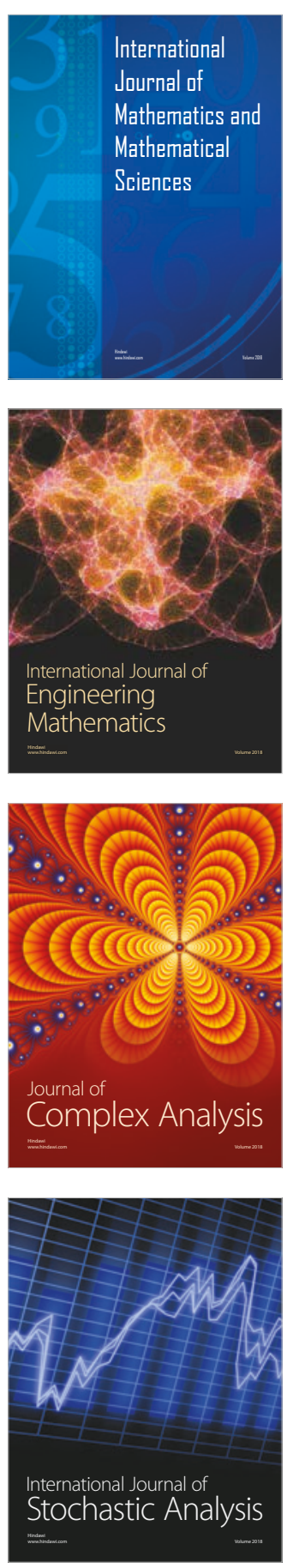
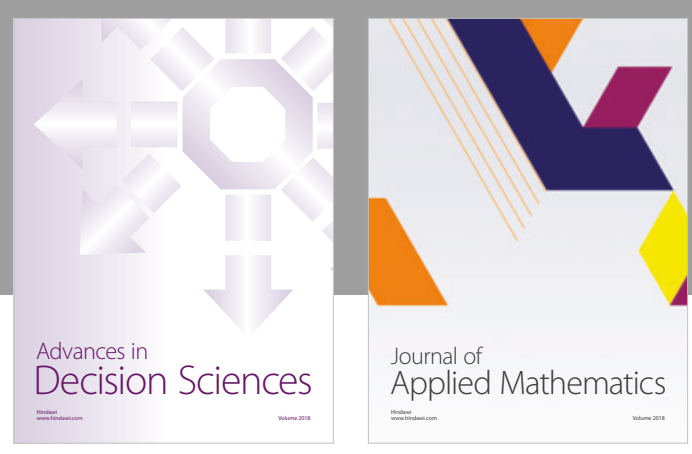

Journal of

Applied Mathematics
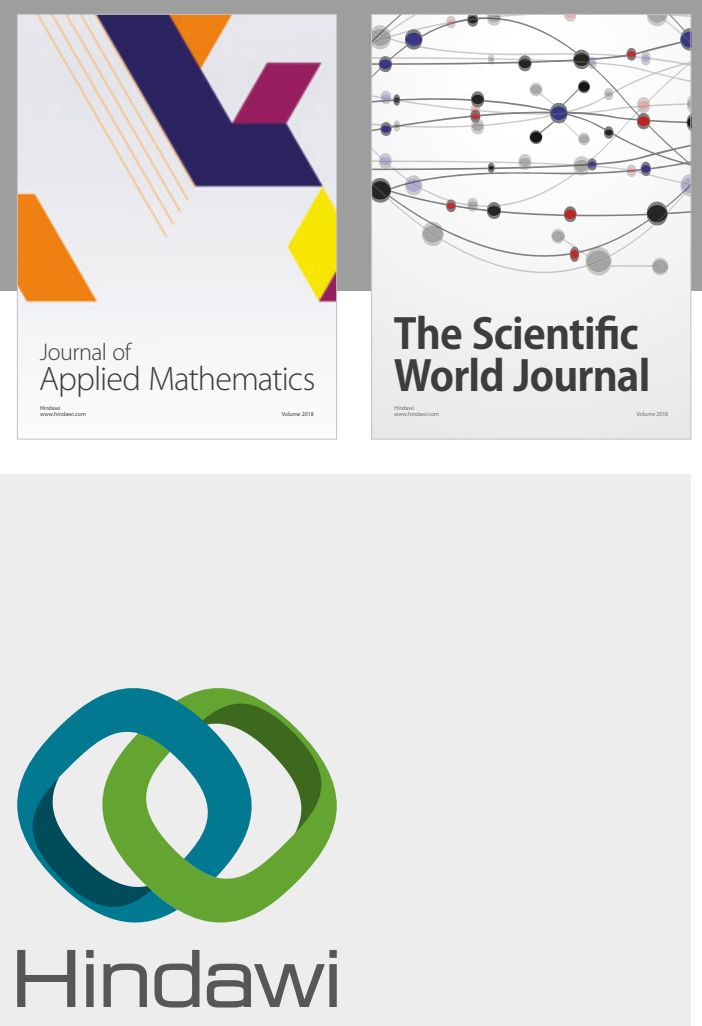

Submit your manuscripts at

www.hindawi.com

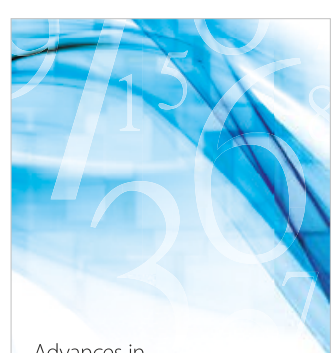

Advances in
Numerical Analysis
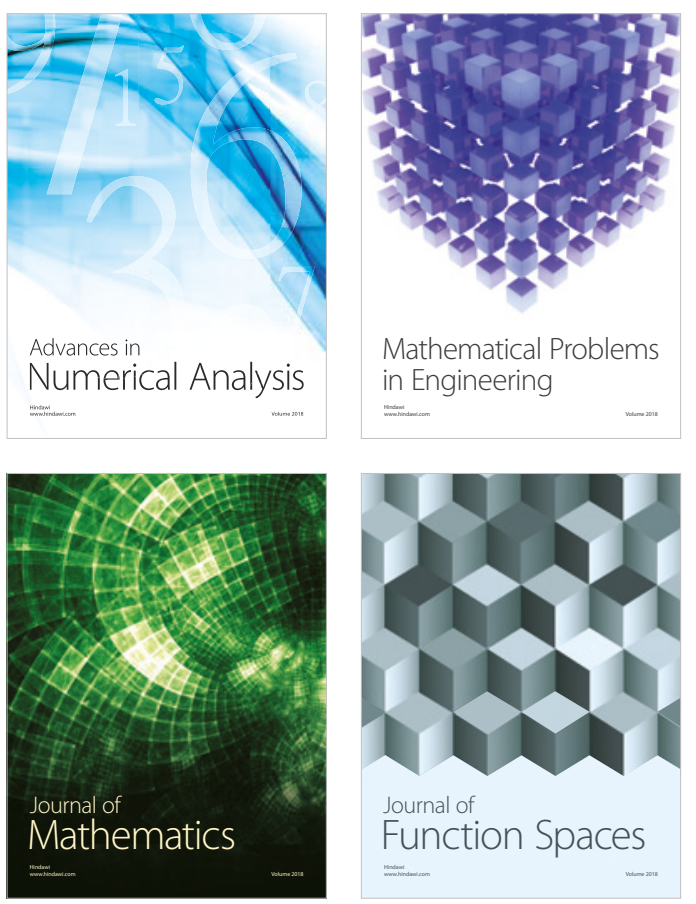

Mathematical Problems in Engineering

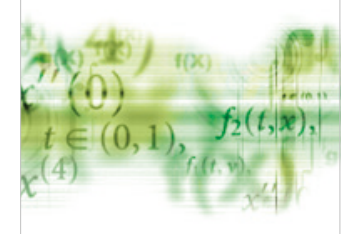

International Journal of

Differential Equations

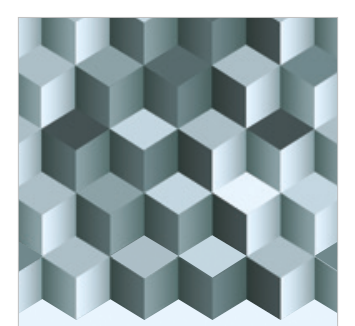

Journal of

Function Spaces
The Scientific

World Journal

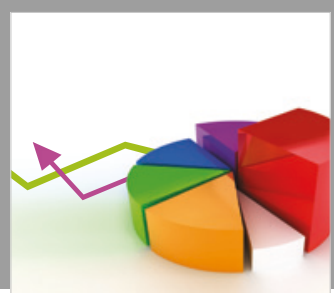

Journal of

Probability and Statistics
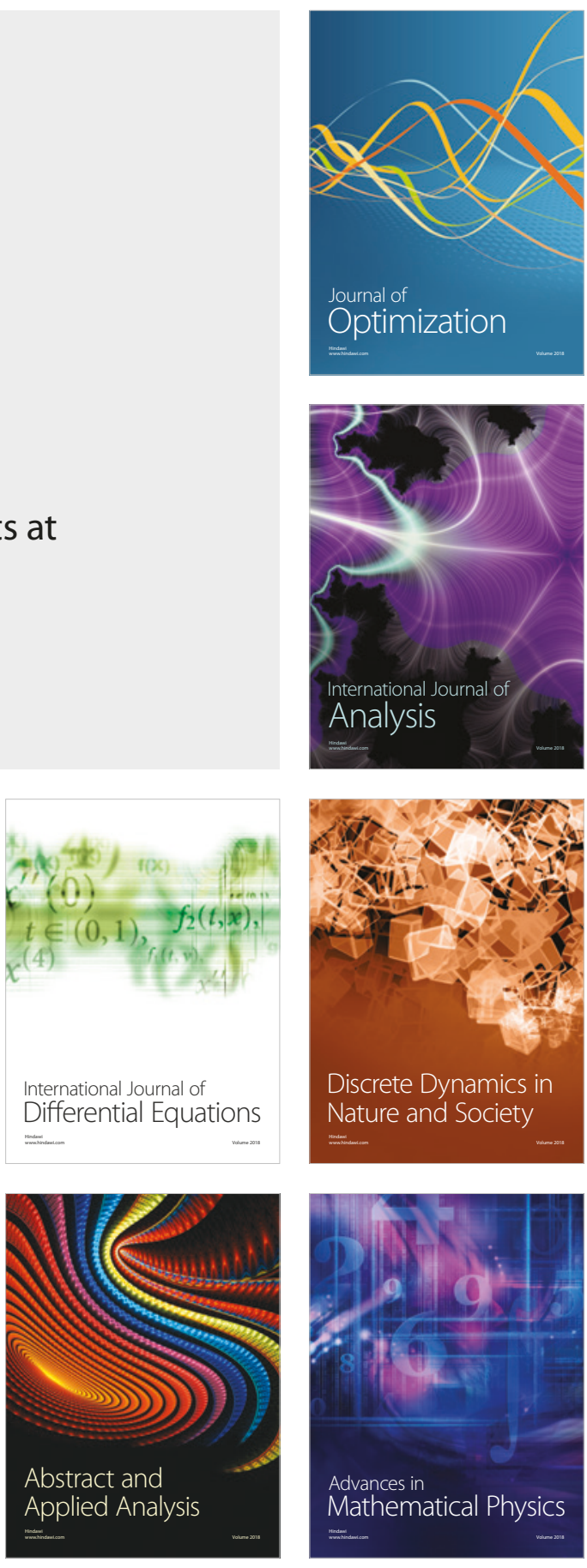